NISTIR 7689

\title{
INTRODUCTION OF WAVE SET-UP EFFECTS AND MASS FLUX TO THE SEA, LAKE, AND OVERLAND SURGES FROM HURRICANES (SLOSH) MODEL
}



NISTIR 7689

\title{
INTRODUCTION OF WAVE SET-UP EFFECTS AND MASS FLUX TO THE SEA, LAKE, AND OVERLAND SURGES FROM HURRICANES (SLOSH) MODEL
}

\author{
Long T. Phan \\ National Institute of Standards and Technology \\ Gaithersburg, MD 28099
}

Donald N. Slinn

Associate Professor

and

Shaun W. Kline

Graduate Research Fellow

University of Florida

Department of Civil and Coastal Engineering

548 Weil Hall

Gainesville, Florida 32611

Grant 60NANB8D8103

May 2010

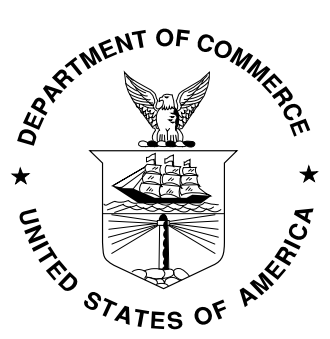

U.S. Department of Commerce

Gary Locke, Secretary

National Institute of Standards and Technology

Pat Gallagher, Director 
(C) 2010 


\section{ACKNOWLEDGEMENTS}

The authors would like to thank the following units and individuals from the U.S.

Department of Commerce for the contributions and technical guidance they provided throughout this study: Dr. Long T. Phan of the Building and Fire Research Laboratory (BFRL), National Institute of Standards and Technology (NIST); Drs. Bob Glahn, Mark A. McInerney, Arthur A. Taylor, and Wilson Shaffer of the Meteorological Development Laboratory (MDL), National Oceanic and Atmospheric Administration (NOAA); and Dr. Stephen Baig (retired) of the National Hurricane Center (NHC), NOAA. 


\section{TABLE OF CONTENTS}

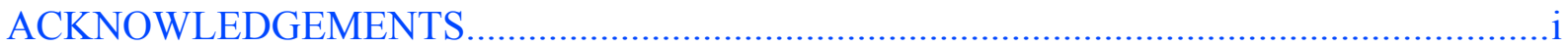

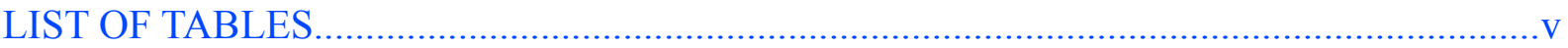

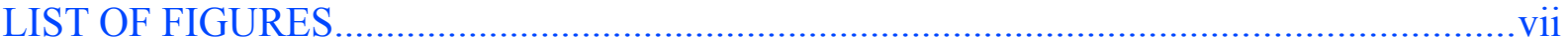

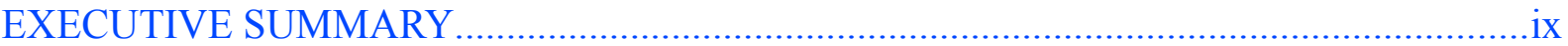

\section{CHAPTER 1}

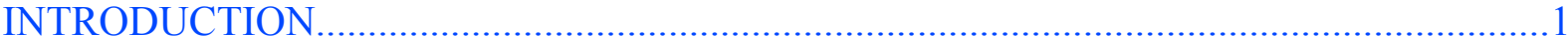

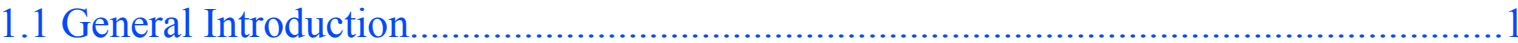

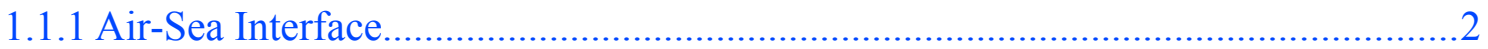

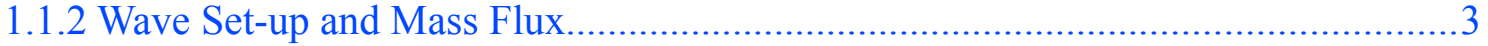

1.1.3 Bathymetry and Other Effects........................................................................

1.2 Storm Surge Model..................................................................................................

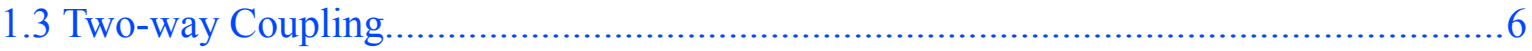

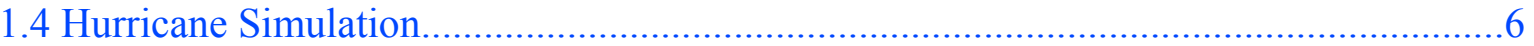

\section{CHAPTER 2}

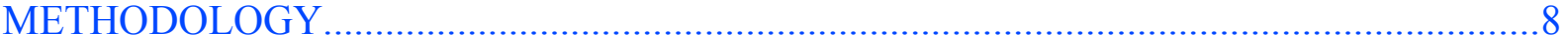

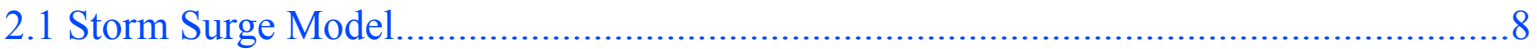

2.1.1 SLOSH Computational Grid......................................................................... 12

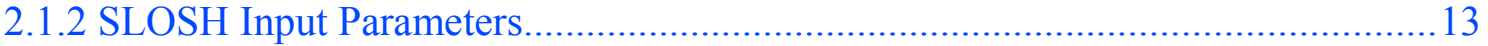

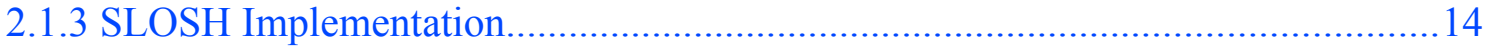

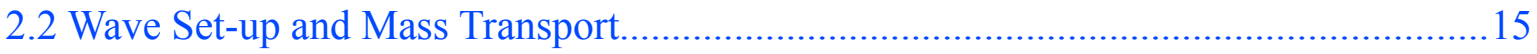

2.2.1 SWAN Computational Grid.................................................................... 15

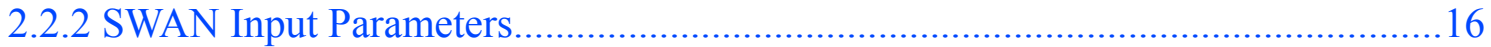

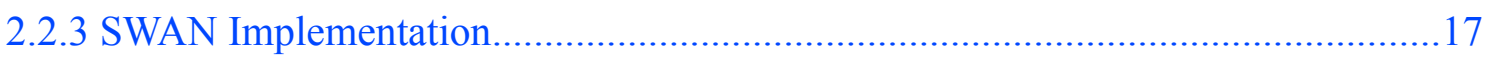

2.3 Two-way Coupling ...................................................................................... 17

\section{CHAPTER 3}

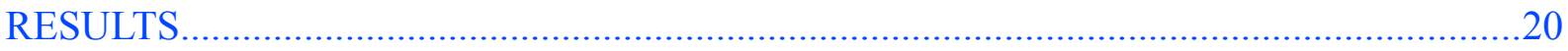

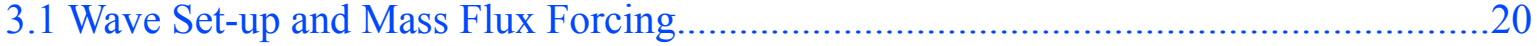

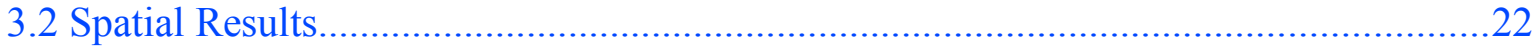


3.2.1 Maximum Storm Tide Levels.....................................................................23

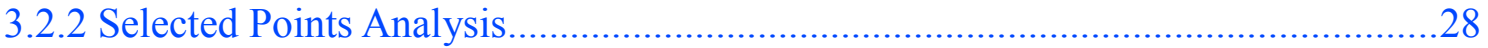

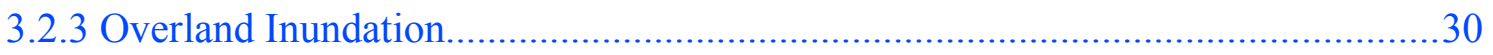

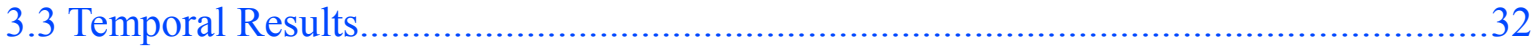

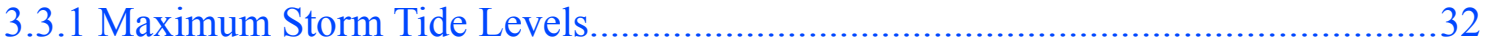

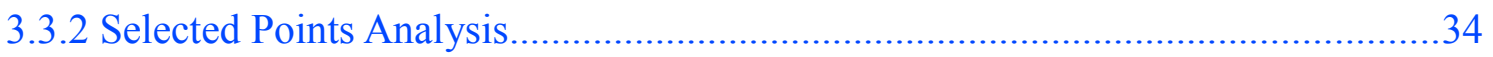

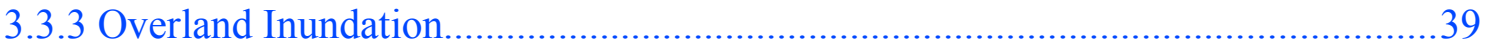

3.4 Hurricane Andrew Hindcast......................................................................... 42

\section{CHAPTER 4}

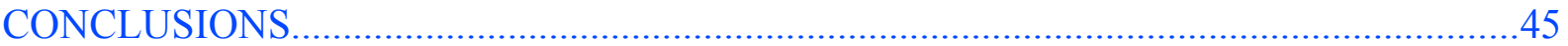

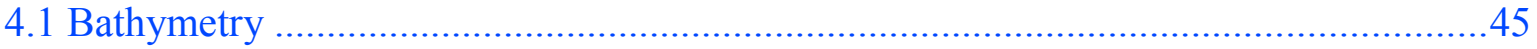

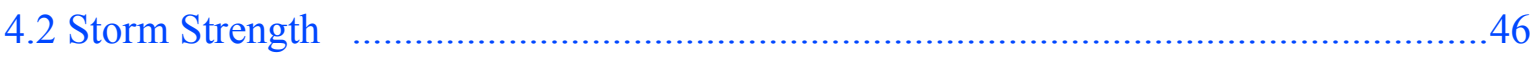

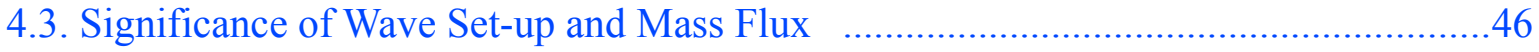

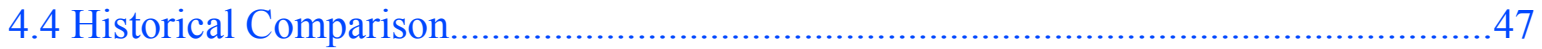

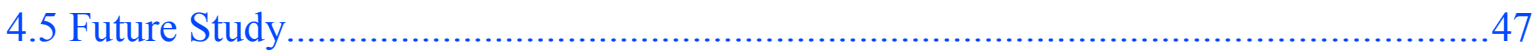

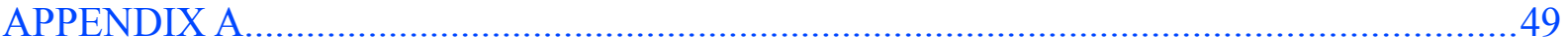

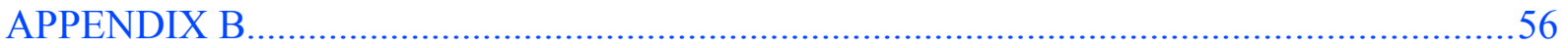

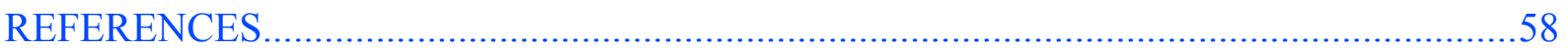




\section{LIST OF TABLES}

$\underline{\text { Tb. }} \quad \underline{P g}$.

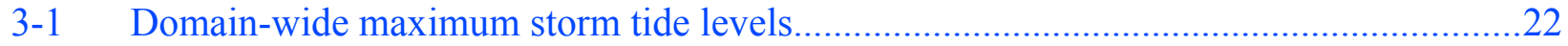

3-2 Storm surge levels outside SLOSH error range.........................................................25

3-3 Coordinates and descriptions of selected analyzed points.........................................27

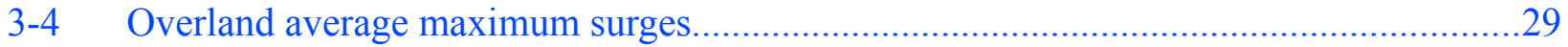




\section{LIST OF FIGURES}

Fig. $\quad \underline{\text { Pg. }}$

2-1 SLOSH ETPA and HMIA computational grids on latitude-longitude axes.....................12

2-2 SWAN computational grids with SLOSH grid overlays.............................................15

3-1 Maximum significant wave heights and mass flux velocities for Category 1 storm.........19

3-2 Maximum wave-induced stresses for Category 1 storm...........................................21

3-3 Zoomed maximum storm tide levels over Tampa Bay for Category 1 storm..................23

3-4 Maximum surge comparison of wave and wind stress and wind stress only.................24

3-5 Maximum surge comparison of both wave components and wind stress only................24

3-6 Percent difference histogram for Category 1 storm................................................26

3-7 Maximum surges at selected points.....................................................................28

3-8 Spatial distribution of overland storm surge levels.................................................30

3-9 Maximum surges at each time step for all storm simulations.......................................32

3-10 Hourly storm surge levels at ETPA point 2984 for Category 1 hurricane.......................33

3-11 Hourly storm surge levels at ETPA point 2984 for Category 4 hurricane........................34

3-12 Hourly storm surge levels at ETPA point 5143 for Category 1 hurricane........................35

3-13 Hourly storm surge levels at ETPA point 5143 for Category 4 hurricane.......................36

3-14 Storm surge levels at each time step at HMIA point 8551 for Hurricane Andrew...........37

3-15 Temporal progression of overland surge levels for Category 1 storm.............................38

3-16 Temporal progression of overland surge levels for Category 4 storm............................39

3-17 Temporal progression of overland surge levels for Hurricane Andrew.........................40

3-18 Storm surge levels at each time step at HMIA point 6042 for Hurricane Andrew...........41 


\section{EXECUTIVE SUMMARY}

Hurricanes wreak havoc on the lives and infrastructure of coastal communities. Storm surge, a local rise in sea elevations, is perhaps the most devastating element of these tropical cyclones. Storm surge depends on the tidal stage, barometric pressure, Coriolis effect, wind stress, and wave forcing, as well as the local bathymetry. In the past, many storm surge numerical models, such as Sea, Lake, and Overland Surges from Hurricanes (SLOSH) (JeLESNIANSKi et al, 1992), neglect wave forcing components to conserve computational efficiency. However, numerous situations necessitate the inclusion of waves' effects to more correctly model the surge both spatially and temporally.

In its effort to characterize the combined effects of hurricane hazards (hurricane wind, storm surge, and waves) for use in developing structural design criteria for coastal structures, the Building and Fire Research Laboratory (BFRL) of the National Institute of Standards and Technology (NIST) - in collaboration with the Meteorological Development Laboratory (MDL) and the Oceanic and Atmospheric Research (OAR) of the National Oceanic and Atmospheric Administration (NOAA) - have developed a methodology that incorporates hurricane science, hydrology, probabilistic methods, and structural engineering needs for use in developing site specific, risk-based design criteria for coastal structures subjected to the above hurricane hazards (PhAn et al, 2007). This early effort utilizes program SLOSH for hydrodynamic simulations without consideration of wave effects. Recognizing that wave set-up and mass flux might have a significant influence on total storm surge levels, the BFRL/NIST then collaborated with the National Hurricane Center (NHC) of NOAA to provide funding (NIST Grant 60NANB8D8103) and technical guidance to the University of Florida/Department of Civil and Coastal 
Engineering) for the incorporation of a wave model into the SLOSH model to extend its capability. The result of this effort is described in this report.

We chose two wave forcing components, that is, set-up from wave stresses and mass flux transport, to incorporate into the SLOSH storm surge model through a two-way coupling methodology. Our aim was to better understand the relative contribution of each effect and their relationship to both storm strength and bathymetry.

To this end, we conducted numerous tests of different forcing variations: wind-stress only, wind and wave stresses, and wind and wave stresses with mass flux transport. These options were simulated on three hurricanes and two SLOSH basins. The storms range in intensity from a Category 1 (wind speed of $34 \mathrm{~m} / \mathrm{s}$ ) to Hurricane Andrew, a Category 5 storm (wind speed of $74 \mathrm{~m} / \mathrm{s}$ ). Our two basins were chosen for bathymetric contrast: Tampa Bay, a shallow and gentle shelf, and Miami, which has a steeper and deeper shelf. Wave stresses and mass transports were obtained using the Simulating Waves Nearshore (SWAN) third-generation wave model with time dependent water level and wind inputs from the SLOSH wind-stress-only test.

We determined that the impact of wave set-up and mass flux to storm surge levels varies between locations - even for the same storm in the same basin - proving that the interaction between the wind and wave forcing components is indeed complex. On average, however, the addition of the wave set-up and mass flux raised the maximum storm surge levels 10 to 30 percent, although isolated positions experience increased well above 100 percent. We also looked at the effects of the wave forcing on specific points and overland inundation. We found that the largest relative contributions to the wave stress occurs in the Tampa Basin, which can be 
attributed to the differences in the storm diameter, intensity, and the complex interactions between the storm and the local topography and bathymetry of the bays themselves. Further, we found wave forcing components contributed the most increase by percentage for the weaker Category 1 storm than during the stronger hurricane simulations. This result does not imply that wave forcing is not of importance for Category 4 and 5 storms, only that wind stresses are responsible for a larger percentage of the overall storm surge. 


\section{CHAPTER 1}

\section{INTRODUCTION}

\subsection{GENERAL INTRODUCTION}

Tropical cyclones form in tropical or subtropical waters as convection occurs around lowpressure systems. In turn, winds circulate around the center of the storm (Holland, 1993). In the northern Atlantic Ocean, these disturbances are referred to as hurricanes when their maximum sustained winds exceeds $74 \mathrm{mph}(33 \mathrm{~m} / \mathrm{s})$. Hurricanes devastate the Atlantic and Gulf coasts of the southeastern United States, destroying infrastructure and dwellings, while placing countless lives in peril. Perhaps the most dangerous element of hurricanes is the associated storm tide. Commonly referred to as a storm surge, it is a local rise in sea elevations due to the presence of low-pressure storms. Hurricane Katrina made landfall on the Gulf of Mexico coast in August, 2005, resulting in a storm tide of 28 feet $(8.5 \mathrm{~m})$, inundating areas of Mississippi and Louisiana for weeks (KNABB, 2006). Less intense hurricanes can still cause several feet of coastal flooding.

The storm tide has four main components. The first is the tidal stage. Coastal locations experience either diurnal (one high tide, one low tide per day), semidiurnal (two high, two low), or mixed (like semidiurnal, but with unequal high and low) tides. In the United States, the Gulf Coast sees mixed or semidiurnal microtidal ( $<2$ m magnitude) events, while the Atlantic coast has diurnal mesotidal (2-4 m magnitude) events (PINET, 1998). The tidal stage during a hurricane's landfall can profoundly effect the resulting storm tide, since the mean sea elevation might fluctuate as much as the other three surge components combined. Ignoring the tidal stage does not bias storm surge results positively or negatively; high and low tides occur with the same frequency and magnitude. Instead, they merely present an envelope of best/worst case scenarios. 
The second component is the barometric tide, which is the sea surface's response to the low pressure at the center of the storm. This rise is essentially due to water being drawn up into the eye of the hurricane. Ambient atmospheric pressure fluctuates around 1012 millibars (mb). Every millibar drop in pressure causes a centimeter rise in the local sea level in deep water (Anthes, 1982). To date, the lowest pressure measured in a hurricane is $882 \mathrm{mb}$ in Hurricane Wilma, as it moved through the eastern Caribbean in 2005 ( $\mathrm{PASCH}, 2006)$. This pressure resulted in an approximate $1.38 \mathrm{~m}$ sea level rise at the storm's center. Although hurricanes typically weaken as they approach the shore, horizontal convergence can increase the associated barometric surge tide. Ignoring the barometric tide would under-predict actual surge levels.

\subsubsection{Air-Sea Interface}

The wind stress tide, the third component, is caused by wind forces acting on the water surface. The storm's winds "push" water to the shore as it makes landfall, causing a build-up near the shoreline. Since hurricane winds can often reach upwards of $125 \mathrm{mph}(200 \mathrm{~km} / \mathrm{hr})$, this contribution is usually dominant compared with the other components.

Interaction between the sea and atmosphere boundary causes energy to be transferred from a hurricane's winds to the water column; this interface has been broadly studied (Geernaert, 1990; Donelan et al, 1993; Donelan, 1998; Grachev et al, 2003). Most studies approximate wind stress per unit mass using Eq. 1-1. Different approaches to the drag coefficient result in up to a $0.5 \mathrm{~m}$ difference in storm surge predictions (WEAver, 2004). However, those effects were not explored in this study. The storm surge model uses an empirically derived constant drag coefficient, whereas the third-generation wave model defines the drag coefficient as a function of the wind speed. 


$$
\vec{\tau}=c_{d} \frac{\rho_{\text {air }}}{\rho_{\text {sw }}}|\vec{W}| \vec{W}
$$

where

$\tau$ - surface wind stress per unit mass

$c_{d}$ - dimensionless drag coefficient

$\rho_{\text {air }}$ - density of air

$\rho_{s w}$ - density of sea water

$W$ - wind velocity vector at 10 meters above sea surface

\subsubsection{Wave Set-up and Mass Flux}

The fourth constituent of storm surge, wave set-up, is the transfer of momentum from breaking waves to the water column (DeAn and Dalrymple, 2002). The momentum flux due to waves is called radiation stress (Longuett-Higgins and Stewart, 1964). To conserve energy, waves exchange their momentum with the water column. Far offshore, before they break, waves gain momentum, causing the mean sea level to decrease. When waves shoal and eventually break near the shore, their radiation stresses are imparted into the water column. This transfer occurs rapidly, forcing the mean sea level to rise. Wave set-up is primarily limited to the surf zone where wave breaking typically occurs. Theoretical computations of the wave set-up contribution on a steady-state, monotonically decreasing beach profile have found that the maximum wave set-up at the coast should be approximately $20 \%$ of the breaking wave height (Dean and Dalrymple, 2002). For a hurricane producing five meter waves, an additional set-up of one meter can be expected. The Gulf of Mexico is a close natural representation of this idealized case.

Waves also contribute a non-linear effect to the storm tide - mass transport or mass flux. Since wind waves are actually non-linear (narrow, steep crests and broad, shallow troughs), every wave period results in a small net transport of mass in the direction of the wave train. For stronger hurricanes, this mass flux can significantly contribute to the storm tide. STARR (1947) 
determined that Eulerian mass transport can be averaged over the water column and through time

(Eq. 1-2). This result demonstrates how larger hurricane-induced waves can lead to considerable shoreward currents; mass flux is dependent only on the water depth, $h+\zeta$, and wave height, $H$.

For a straight, steady-state shoreline, the Eulerian transport is equivalent and opposite to the wave-induced mass transport (Sмітн, 2006).

$$
\overline{w_{\text {mass flux }}}=\frac{M^{W}}{\rho_{s w}(h+\zeta)}=\frac{\overline{\int_{-h}^{\zeta} \rho_{s w} w(x, \zeta) d z}}{\rho_{s w}(h+\zeta)}=\frac{E}{C \rho_{s w} h}=\frac{1}{8} \frac{\sqrt{g} H^{2}}{(h+\zeta)^{3 / 2}}
$$

where

$w_{\text {mass flux }}$ - depth-averaged time-mean horizontal velocity

$M^{W}$ - wave-induced mass transport

$\rho_{s w}$ - reference density of sea water $\left(1.979\right.$ slugs $/ \mathrm{ft}^{3}$ or $\left.1020 \mathrm{~kg} / \mathrm{m}^{3}\right)$

$h$ - mean water depth

$\zeta$ - free surface elevation above the mean sea level

$w(x, \zeta)$ - horizontal velocity

$z$ - vertical direction

$E=\frac{1}{8} \rho_{s w} g H^{2}-$ total energy per unit surface area

$C=\sqrt{g h}-$ shallow water phase speed

$g$ - acceleration due to Earth's gravity

$H$ - wave height

\subsubsection{Bathymetry and Other Effects}

Bathymetry also plays a vital role in determining storm tide levels. Shallow, gentlesloping areas, such as the Gulf of Mexico, often see higher storm tides than steeper shelves like the Atlantic coast of Florida from equivalent storms. This phenomenon occurs because a storm tide can be diffused away from the hurricane in deep water, whereas in shallow water it remains focused to the coast. For a one-dimensional case, the steady state solution for storm surge from wind-only forcing is shown in Eq. 1-3 (Dean and Dalrymple, 1991).

$$
\frac{\partial \zeta}{\partial x}=\frac{n \tau_{z x}(\zeta)}{\rho_{s w} g(h+\zeta)}
$$

where

$x$ - cross-shore direction 
$n=1-\left[\frac{\tau_{z x}(-h)}{\tau_{z x}(\zeta)}\right]$ (must be greater than 1)

$\tau_{z x}(\zeta)$ - surface shear stress

$\tau_{z x}(-h)$ - bottom shear stress

Other factors that influence storm surge levels include the Coriolis effect, rainfall, and river discharges. The Coriolis effect occurs because the Earth's rotation bends currents counterclockwise in the northern hemisphere. During a hurricane, the effect can be especially relevant if currents are bent perpendicular to the coast. The Rossby number, a ratio of inertial to Coriolis forces, can be used to evaluate the relative importance of this component. Large Rossby numbers indicate the Coriolis tide will not contribute significantly to the overall storm tide (KANtha, 2000). Rainfall and river discharges can locally influence storm tide levels, but are generally ignored in storm surge modeling.

\subsection{STORM SURGE MODEL}

The numerical model we used to compute sea surface level is Sea, Lake, and Overland Surges from Hurricanes (SLOSH). The model solves the conservation of mass and momentum equations integrated over the water column spatially and temporally, while treating the coastline as a physical boundary. In historical comparisons, the SLOSH model has been found to be accurate to \pm 20 percent (JElesnianski et al, 1992). We predict the water elevations over the test basin with three test cases:

- Wind stress only (SLOSH model unedited)

- Wind stress and wave radiation stress

- Wind stress, wave radiation stress, and mass flux

We can then analyze the results to determine the relative significance of each wave contribution to storm surge.

The SLOSH model incorporates approximately forty gridded basins that cover the eastern 
and southern coasts of the United States. Two basins were chosen for comparison: Elliptical Tampa Bay Basin (ETPA) and Hyperbolic Miami Basin (HMIA). These two basins were selected to compare bathymetry's impact on wave forcing. The Tampa Bay basin exemplifies a shallow, gradually sloping shelf, whereas the Miami basin is both steeper and deeper.

\subsection{TWO-WAY COUPLING}

To study the effect of wave set-up and mass flux effects on the storm surge model we used a two-way coupling methodology. By this, we mean water levels and wind velocities from the time dependent storm surge simulation are passed to a wave model. For this purpose, we

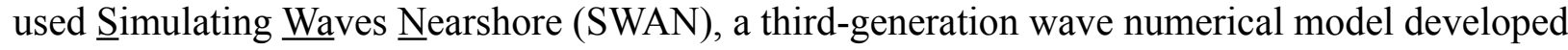
by Delft University (Boois et al, 2004). The model simulates wave fields over a Cartesian grid system from its bathymetry and optional inputs at each time step: currents (assumed to be zero), wind, and water levels. This aspect of the two-way coupling changes the wave height distributions in coastal waters. The second component of the two-way coupling passes the forces from breaking waves and mass flux transport back to the storm surge model. The results from each of the three cases from Section 1.2 are then analyzed for spatial and temporal differences.

\subsection{HURRICANE SIMULATION}

For our experiment, we chose a representative test storm (etpa_SLOSHtrk998) provided by the NWS (a significant historical hurricane would have been preferred but no such accurate records exist for the ETPA basin). This hurricane has maximum wind strength of $34 \mathrm{~m} / \mathrm{s}$ (75 mph) and would be classified as a Category 1 hurricane on the Saffir-Simpson scale. It was selected because of its northeastward trajectory and landfall location just north of Tampa Bay. Preliminary tests with this track and other tests storms (namely etpa_SLOSHtrk99 and 
etpa_SLOSHtrk2721) showed that this trajectory led to maximum storm surge levels in and around Tampa Bay. Each test storm file has hourly track points, a radius of maximum winds, and maximum central winds. However, by manipulating these values, we can alter the test hurricane into a stronger storm. To test the impact of a storm's strength on storm surge values, we altered this test storm into a Category 4 hurricane; by scaling the maximum winds by a factor of 1.75 , we created a maximum wind strength of $60 \mathrm{~m} / \mathrm{s}(130 \mathrm{mph})$.

We also performed a hindcast analysis on Hurricane Andrew in the HMIA basin. On early morning of August 24, 1992, Hurricane Andrew made landfall at Elliot Key, Florida, with maximum sustained winds of $165 \mathrm{mph}$, followed shortly by a second landfall at Homestead, Florida (Landsen et al, 2004). The last Category 5 Hurricane to make landfall in the United States, Andrew caused approximately $\$ 25$ billion in damages in Florida and was responsible for 65 deaths (HERBERT et al, 1992; RAPPAPORT, 1993). We modeled the storm while it remained within the HMIA boundaries, a total time of about sixteen hours. The NOAA National Ocean Service Center for Operation Oceanographic Products and Services (NOAA NOS CO-OPS) website contains a plethora of historical buoy data, but, unfortunately, no time dependent sea level recorders were deployed in the region during the time of Andrew's strike. Hence, the historical comparison can only be made for the maximum storm tide levels recorded at the Atlantic coast.

Hurricane Andrew does provide another opportunity for comparison; it can be compared to the Category 4 results from Tampa Bay to gain an assessment of bathymetry's impact on wave set-up and mass transport. The Category 1 and 4 hurricane simulations over Tampa Bay additionally allow for an examination of two storms with identical characteristics, except for scaled maximum winds, over the same bathymetry. Hence, we can answer how much the strength of the storm impacts the relative contributions of the two forcing options. 


\section{CHAPTER 2}

\section{METHODOLOGY}

\subsection{STORM SURGE MODEL}

Storm tide levels were predicted using SLOSH numerical model created by the National Weather Service's (NWS) Meteorological Development Laboratory (MDL). SLOSH's primary developers were Chester Jelesnianski, Jye Chen, and Wilson Shaffer (JeLESNiAnski et al, 1992). Horizontal transports are solved through application of the Navier-Stokes momentum equations for an incompressible and turbulent flow. For a generic real plane, the momentum equations can be written so that the time rate of change of the velocity vector is equivalent to four forces: pressure, Coriolis effect, gravity, and friction. Eqs. 2-1, 2-2 and 2-3 show the expanded equations of motion for the horizontal and vertical velocities after Boussinesq's approximation for incompressible flow (constant density) and hydrostatic pressure are applied. Since the gravitational force only acts in the vertical direction, it does not appear in the horizontal momentum equations. Likewise, Coriolis forcing does not appear in the vertical momentum equation.

$$
\begin{aligned}
& \frac{\partial u}{\partial t}+u \frac{\partial u}{\partial x}+v \frac{\partial u}{\partial y}+w \frac{\partial u}{\partial z}-f v=-\frac{1}{\rho_{s w}} \frac{\partial p}{\partial x}+A_{h}\left[\frac{\partial^{2} u}{\partial x^{2}}+\frac{\partial^{2} u}{\partial y^{2}}\right]+A_{v} \frac{\partial^{2} u}{\partial z^{2}} \\
& \frac{\partial v}{\partial t}+u \frac{\partial v}{\partial x}+v \frac{\partial v}{\partial y}+w \frac{\partial v}{\partial z}+f u=-\frac{1}{\rho_{s w}} \frac{\partial p}{\partial y}+A_{h}\left[\frac{\partial^{2} v}{\partial x^{2}}+\frac{\partial^{2} v}{\partial y^{2}}\right]+A_{v} \frac{\partial^{2} v}{\partial z^{2}} \\
& \frac{\partial w}{\partial t}+u \frac{\partial w}{\partial x}+v \frac{\partial w}{\partial y}+w \frac{\partial w}{\partial z}=-\frac{1}{\rho_{s w}} \frac{\partial p}{\partial z}-g+A_{h}\left[\frac{\partial^{2} w}{\partial x^{2}}+\frac{\partial^{2} w}{\partial y^{2}}\right]+A_{v} \frac{\partial^{2} w}{\partial z^{2}}
\end{aligned}
$$

where $u(x, y, z, t), v(x, y, z, t)$ - time-averaged horizontal velocities 
$w(x, y, z, t)$ - time-averaged vertical velocity

$t$ - time

$x, y$ - horizontal coordinates

$z$ - vertical coordinate

$f=2 \Omega \sin \varphi-$ Coriolis parameter

$\rho_{s w}$ - reference density of sea water $\left(1.979 \mathrm{slugs} / \mathrm{ft}^{3}\right.$ or $\left.1020 \mathrm{~kg} / \mathrm{m}^{3}\right)$

$p$ - time-averaged pressure

$A_{h}$ - horizontal eddy viscosity coefficient

$A_{v}$ - vertical eddy viscosity coefficients

$\Omega$ - angular speed of the Earth $\left(7.29 \times 10^{-5} \mathrm{rad} / \mathrm{s}\right)$

$\varphi-$ latitude (degrees)

SLOSH first negates vertical velocity, w, and horizontal eddy viscosity, $A_{h}$, since both are several orders of magnitude smaller than their perpendicular counterparts. Further, the model does not account for the advective terms (the second, third, and fourth terms on the left hand side of Eqs. 2-1, 2-2 and 2-3) because the storm tide only shows a sensitivity to them in localized areas with strong current gradients (WhitAKER et al, 1975; JELESNIANSKi et al, 1992). SLOSH does incorporate small amplitude effects to compensate for this omission. These assumptions, along with the application of the definition of shear stresses (see below), yield Eqs. 2-4 and 2-5, which demonstrate that the horizontal velocities do not vary vertically through the water column. Eq. 2-3 is reduced to a relationship between the vertical pressure gradient and the product of gravity and sea water density (Eq. 2-6). Thus, pressure is no longer a dependent variable in the horizontal momentum equations.

$$
\begin{gathered}
\frac{\partial u}{\partial t}-f v=-\frac{1}{\rho_{s w}} \frac{\partial p}{\partial x}+\frac{1}{\rho_{s w}}\left[\frac{\partial \tau_{z x}}{\partial z}\right] \\
\frac{\partial v}{\partial t}+f u=-\frac{1}{\rho_{s w}} \frac{\partial p}{\partial x}+\frac{1}{\rho_{s w}}\left[\frac{\partial \tau_{z y}}{\partial z}\right] \\
\frac{\partial p}{\partial z}=-\rho_{s w} g
\end{gathered}
$$


where

$\tau_{z x}=\mu\left[\frac{\partial u}{\partial z}\right]-$ viscous shear stress

$\tau_{z y}=\mu\left[\frac{\partial v}{\partial z}\right]-$ viscous shear stress

$\mu=v \rho_{s w}-$ molecular viscosity

These equations are then translated to a complex plane $(\mathrm{z}=\mathrm{x}+\mathrm{iy})$ and applied to the horizontal momentum, Eq. 2-7, which defines the real and imaginary components of transport by vertically integrating the complex horizontal velocity over the entire water column.

$$
M=U+i V=\int_{-h}^{\zeta} q d z=(h+\zeta) \int_{0}^{1} q d z^{\prime}
$$

where

$M$ - horizontal transport

$U$ - real component of horizontal transport

$V$ - imaginary component of horizontal transport

$z$ - vertical coordinate

$z^{\prime}=\frac{h+z}{h+\zeta}-$ vertical coordinate transformation

$q=u+i v-$ complex horizontal velocity (real and imaginary components)

At this point, the complex horizontal transport equations can be solved by specifying boundary conditions (Eqs. 2-8 and 2-9). Two noteworthy conditions are the treatment of the viscous shear stresses. At the bed, it is assumed to be the complex horizontal velocity $\mathrm{q}_{\mathrm{bed}}$, multiplied by a slip coefficient, s (Platzman, 1963; Jelesnianski, 1967). The surface shear stress per unit mass takes the form of Eq. 1-1. The bottom stress is "absorbed" into six terms that are a function of the water depth, $\mathrm{h}+\zeta$, and modify each right-hand-side term of Eqs. 2-8 and 2-9. Undetermined coefficients hidden in these bottom stress terms, along with the two surface stress terms, were all set empirically through historical hindcasts of 43 landfall hurricanes on the Gulf and Atlantic coasts of the United States (Jelesnianski et al, 1992). 


$$
\begin{aligned}
& \frac{\partial U}{\partial t}=-g(h+\zeta)\left[B_{r} \frac{\partial\left(\boldsymbol{\zeta}-\boldsymbol{\zeta}_{0}\right)}{\partial x}+B_{i} \frac{\partial\left(\boldsymbol{\zeta}-\boldsymbol{\zeta}_{0}\right)}{\partial y}\right]+f\left(A_{r} V+A_{i} U\right)+C_{r} \boldsymbol{\tau}_{x}-C_{i} \boldsymbol{\tau}_{y} \\
& \frac{\partial V}{\partial t}=-g(h+\zeta)\left[B_{r} \frac{\partial\left(\zeta-\boldsymbol{\zeta}_{0}\right)}{\partial y}+B_{i} \frac{\partial\left(\zeta-\boldsymbol{\zeta}_{0}\right)}{\partial x}\right]+f\left(A_{r} U+A_{i} V\right)+C_{r} \boldsymbol{\tau}_{y}+C_{i} \boldsymbol{\tau}_{x}
\end{aligned}
$$

where

$A_{i}, A_{r}, B_{i}, B_{n}, C_{i}, C_{r}$ - bottom stress terms

$\zeta_{0}$ - mean sea level elevation

$\tau_{\mathrm{x}},-$ real surface stress per unit mass component

$\tau_{\mathrm{y}}-$ imaginary surface stress per unit mass component

The model applies the conservation law for mass to relate these horizontal transports to a rise in sea level. Eq. 2-10 shows the continuity equation with Boussinesq's approximation for incompressible flow. Vertical velocity is again assumed to be negligible. Following the same derivation procedure as the momentum equations, the coordinates are translated to the complex plane and the definitions of transport from Eq. 2-7 are applied. SLOSH's form of the continuity equation (Eq. 2-11) results, noting that $\mathrm{x}$ and $\mathrm{y}$ in this equation are the real and imaginary components of the complex plane, respectively.

$$
\begin{aligned}
& \frac{\partial u}{\partial x}+\frac{\partial v}{\partial y}+\frac{\partial w}{\partial z}=0 \\
& \frac{\partial \zeta}{\partial t}=-\frac{\partial U}{\partial x}-\frac{\partial V}{\partial y}
\end{aligned}
$$

Eqs. 2-8, 2-9, and 2-11 are the essence of the SLOSH model. At every time step, the horizontal transports are solved from the pressure, Coriolis, and frictional (shear stress) forces. In turn, these horizontal transports lead to a new surge level, $\zeta$, at every grid location.

A complete derivation of the SLOSH equations of motion can be found in Numerical Computations of Storm Surges with Bottom Stress (Jelesnianski, 1967) and Appendix A of the SLOSH Technical Report (JELESNIANSKi et al, 1992). 


\subsubsection{SLOSH Computational Grid}

SLOSH operates on over forty basins covering nearly the entire eastern and southern seaboards of the United States. Originally, all of these basins were polar grids to allow for both greater resolution near the coast, the focus of storm surge prediction, and also the implementation of simple boundary conditions (JELESNIANSKI et al, 1992). However, many of these original basins have been phased out in favor of elliptical and hyperbolic grids that provide the same advantages offered by polar grid with greater coverage and even finer resolution in areas of interest. The Elliptical Tampa Bay (ETPA) Basin is an elliptical grid with 9090 points that covers Tampa Bay and the adjacent coastline approximately 50 miles north and south (Figure 2-1A). The grid centers around the bay and radiates outward into the Gulf of Mexico. Figure 2-1B shows the Hyperbolic Miami (HMIA) Basin, a hyperbolic grid of 23,750 points that covers the area between Lake Okeechobee and the Bahamas. The ETPA and HMIA basins both have fine resolution (two kilometer spacing) near the coast and much coarser resolution (four
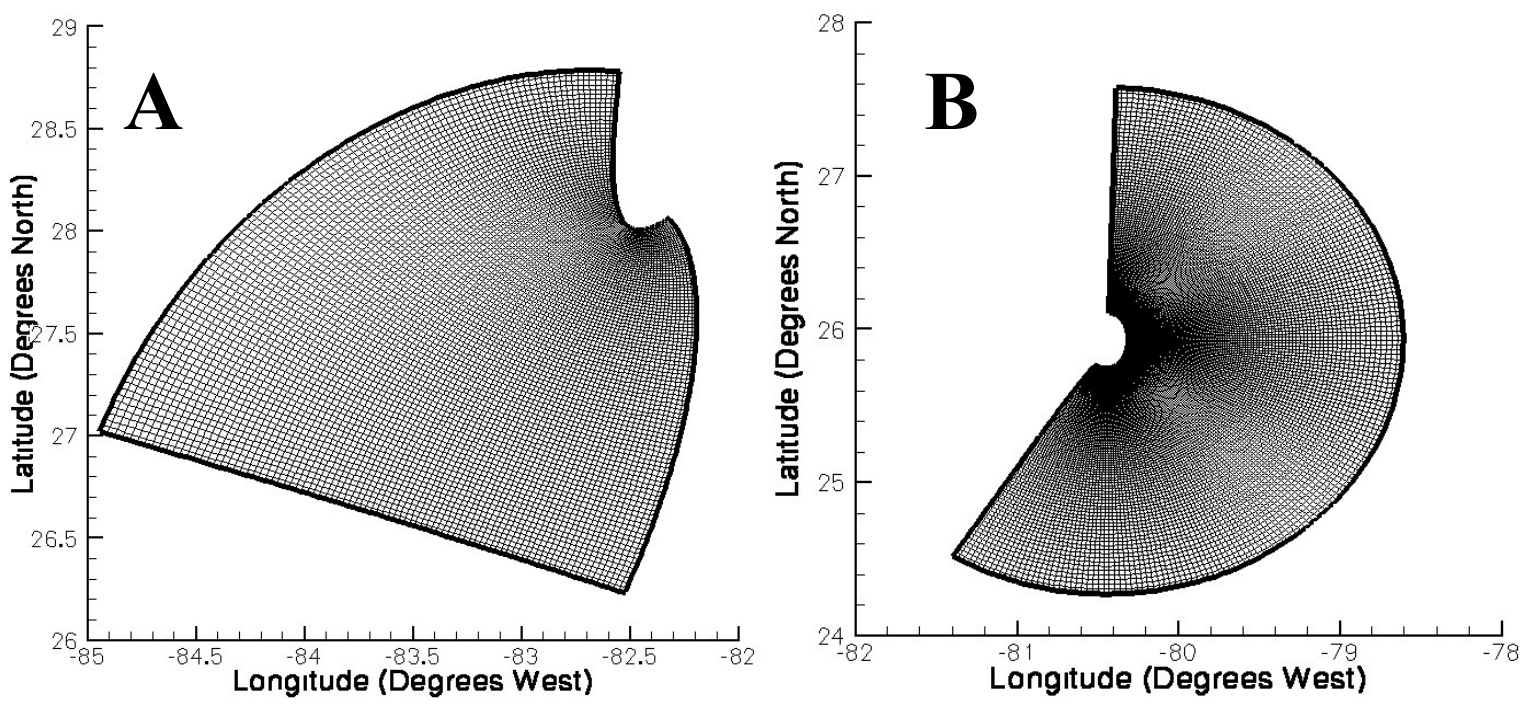

Figure 2-1: SLOSH computational grids on a longitude-latitude grid. Figure A is the Elliptical Tampa Bay Basin (ETPA) and Figure B is the Hyperbolic Miami Basin (HMIA). The grid spacing is approximately $2000 \mathrm{~m}$ near the coasts and $4000 \mathrm{~m}$ in deep water. 
kilometer spacing) in deeper waters of the Gulf and Atlantic, respectively. The bathymetry data for these grids have minimum and maximum cutoff values and range between -290 feet in the Gulf and Atlantic and 40 feet on land.

It should be noted that although all of the inputs and output values of SLOSH are based on real space (longitudinal and latitudinal coordinates for the grid points), a grid transformation to an image plane is used for all computations. SLOSH implements four boundary conditions for this computational grid:

- Zero transport over dry land.

- Surface gradients are replaced by the nearest interior, contiguous point in shallow water.

- Surface gradients are replaced by the storm's hydrostatic gradient in intermediate depths.

- Hydrostatic height of the storm is set at height points of boundary squares in deep water.

\subsubsection{SLOSH Input Parameters}

The SLOSH model's input parameters for a hurricane are its position, size, and intensity. These values are saved in a SLOSH TRK file, which contains up to 100 track points of data. Each point gives the longitudinal and latitudinal coordinates of the storm's center, central pressure, maximum wind speed, radius of maximum winds (distance from center the maximum wind speed is found), and direction . Each point is an hourly progression of the hurricane. An example of a TRK file used in our study can be found in Appendix A.

Wind speeds are calculated at every grid point using the wind speed profile depicted in Eq. 2-12 for a stationary storm (Myers and MaLkin, 1961). At the storm's center and far away from the hurricane, the wind speed tapers off to zero. A vector correction for the storm's motion is added to the stationary wind speed to arrive at the wind vector used in surface shear stress computations (JELESNIANSKI and TAYLOR, 1973).

$$
W_{s}=V_{R} \frac{2 R r}{R^{2}+r^{2}}
$$


where

$W_{s}(r)$ - wind speed for stationary storm

$V_{R}-$ maximum wind speed

$R$ - radius of maximum winds

$r$ - distance from storm's center to grid point

The other input parameters SLOSH requires are the selected basin's grid locations and their associated bathymetry. Subgrid features, such as barriers, can be incorporated, but are not required. Every created basin has its own data file.

\subsubsection{SLOSH Implementation}

Once the above input parameters have been specified, SLOSH can operate. SLOSH was designed to output a REX and ENV file, both of which are viewed using the SLOSH display program. The REX file contains water levels at every grid cell at a specific interval of time and are displayed as time-lapsed animated movies. The ENV file contains the maximum water level at any point over the duration of the storm(s) (MCINERnEy, 2006). Essentially, we wrote the REX file data to a separate water level file at set time steps. Additionally, we wrote out the wind fields across the basin at the same time intervals. These time steps were matched to default SLOSH time steps, which are dependent on the basin and the storm's distance from the coast. These time steps were determined by stability testing on SLOSH's finite difference scheme. The critical time value was set for a Courant number equal or less than 1.0 on the polar grid. For the ETPA grid, a perpetual time step of one hour is used, whereas on the HMIA grid, the time step decreases from fifteen to ten and finally to five minutes as the storm's center nears land. Computations are made sixty times per time step. The output data (wave levels and wind velocities) would be used in the two-way coupling with the wave model. 


\subsection{WAVE SET-UP AND MASS TRANSPORT}

To study wave set-up and mass flux effects on the storm surge, we needed a way to accurately model the wave field, and then interpolate those results to the SLOSH computational grid. To this end, we used the Simulating Waves Nearshore (SWAN) model, created by Delft University. One of the most important outputs from SWAN is time dependent wave-induced stress, or gradient of the radiation stresses, as shown in Eqs. 2-13 and 2-14. These gradients are calculated from a $2^{\text {nd }}$ order central difference scheme everywhere except at the boundaries, which employ a first order forward difference strategy (BooIs et al, 2004). Other noteworthy time dependent variables SWAN can provide are significant wave heights, peak periods, wave direction, and water depths.

$$
\begin{aligned}
& F_{x}=-\frac{\partial S_{x x}}{\partial x}-\frac{\partial S_{x y}}{\partial y} \\
& F_{y}=-\frac{\partial S_{y x}}{\partial x}-\frac{\partial S_{y y}}{\partial y}
\end{aligned}
$$

where

$$
\begin{aligned}
& S_{x x}=\rho g \int\left(n \cos ^{2}(\theta)+n-\frac{1}{2}\right) E d \sigma d \theta \\
& S_{x y}=S_{y x}=\rho g \int(n \cos (\theta) \sin (\theta)) E d \sigma d \theta \\
& S_{y y}=\rho g \int\left(n \sin ^{2}(\theta)+n-\frac{1}{2}\right) E d \sigma d \theta \\
& n=C_{g} / C \\
& C_{g}-\text { group velocity }
\end{aligned}
$$

\subsubsection{SWAN Computational Grid}

The SWAN computational grids were created from NOAA's National Geophysical Data Center's (NGDC) GEODAS system. Figure 2-2A shows the grid used for the Tampa Bay testing. This Cartesian grid covers three longitudinal and latitudinal degrees $\left(83^{\circ} \mathrm{W}\right.$ to $80^{\circ} \mathrm{W}$ and $26^{\circ} \mathrm{N}$ to $29^{\circ} \mathrm{N}$, respectively), completely covering SLOSH's ETPA basin grid. The SWAN grid has a 
uniform spacing of just under two kilometers, chosen to match the finest resolution of the SLOSH grid and allow for meaningful interpolations between the SLOSH and SWAN especially nearshore where waves break and impart their momentum on the water column. The SWAN grid for Miami (Figure 2-2B) was created in the same manner and has the same grid spacing. It covers three longitudinal degrees $\left(78.5^{\circ} \mathrm{W}\right.$ to $\left.81.5^{\circ} \mathrm{W}\right)$ and almost four latitudinal degrees $\left(27.125^{\circ} \mathrm{N}\right.$ to $\left.28.875^{\circ} \mathrm{N}\right)$. In the interest of consistency, we interpolated the SLOSH bathymetric values to the SWAN grid for any points inside the SLOSH grid boundaries. The remaining points outside the SLOSH grid boundaries were not altered, except in the case where bathymetric values exceeded the SLOSH bathymetric range (see Section 2.1.1). In these instances, the bathymetry values were rounded to the appropriate cutoff value.
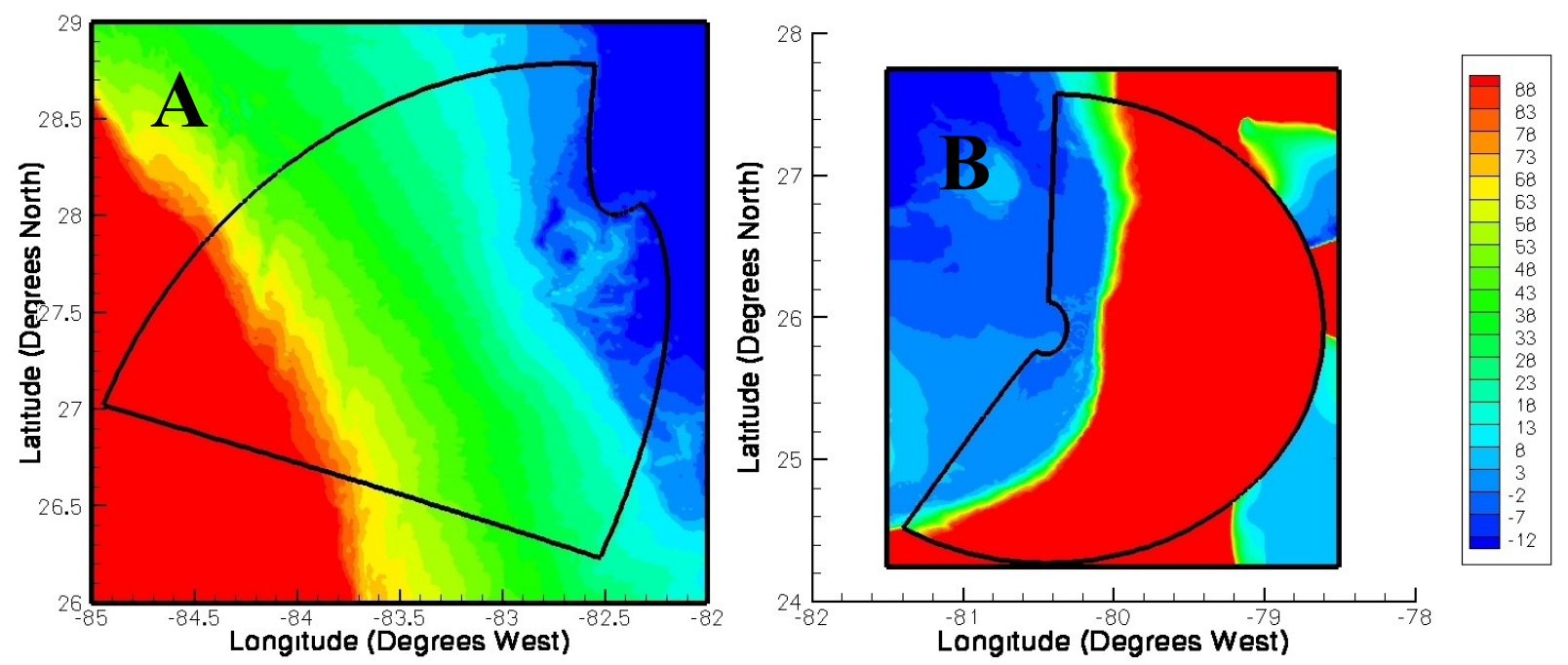

Figure 2-2: SWAN computational grids with SLOSH computational grid overlays. Figure A is the Tampa Bay basin with ETPA overlay and Figure B is the Miami basin with HMIA overlay. The contours on both figures show the bathymetry, which range from $88 \mathrm{~m}$ to $-12 \mathrm{~m}$.

\subsubsection{SWAN Input Parameters}

The SWAN model allows for multiple input grids: depth, water level, currents, wind velocity, and friction. The latter four inputs can be either time dependent or constant. For the 
purposes of this study, currents were assumed to be zero and no time dependent bottom friction terms were used. Instead, the JONSWAP expression for bottom friction dissipation was turned on. The hourly water level and wind velocities from the initial wind-stress-only SLOSH run were interpolated onto the SWAN Cartesian grid.

\subsubsection{SWAN Implementation}

SWAN can produce numerous selected outputs. For our study, we focused on the hourly wave stresses (Eqs. 2-13 and 2-14), significant wave height, wave direction, peak period, and water depth at every grid point. An example of the SWAN input file for the Category 1 hurricane simulation over Tampa Bay can be found in Appendix B of this report.

\subsection{TWO-WAY COUPLING}

As discussed in Section 1.3, SLOSH and SWAN were joined via a two-way coupling method. The first aspect of this task, already mentioned in Section 2.2.2 involved the interpolation of hourly water levels and wind velocities from the unedited SLOSH model computations on either the elliptical or hyperbolic grid onto the SWAN Cartesian grid. For those points outside the SLOSH grid boundaries, wind velocities were assumed to be zero and water levels were made equivalent to the SLOSH datum elevation $(0.00 \mathrm{~m}$ for the Tampa Bay simulations and $0.61 \mathrm{~m}$ for the Hurricane Andrew hindcast). Although these assumptions might cause discrepancies at the SLOSH boundaries where water levels and wind velocities possibly shift dramatically, it should be noted that nearly all of these points are overland or in deep water, far away from the zone of interest nearshore. However, we analyzed the results to ensure that the wave set-up effects and mass flux transport acted away from the SLOSH boundaries. As an extra precaution, we removed these SLOSH boundary points from any analysis.

With these inputs, SWAN then modeled the hourly wave fields, providing time 
dependent wave stresses (Eqs. 2-13 and 2-14), wave heights, peak period, wave direction, and water depth as detailed in Section 2.2.3. Eq. 2-15 along with the definition of depth-averaged time-mean mass flux velocity from Eq. 1-2, was used to determine the horizontal mass flux transport given the time dependent significant wave height, water depth, and wave direction at each grid location.

$$
M_{\text {mass flux }}=U_{\text {mass flux }}+i V_{\text {mass flux }}=(h+\zeta) \overline{w_{\text {mass flux }}}
$$

where

$M_{\text {mass flux }}$ - horizontal transport due to mass transport

$U_{\text {mass flux }}$ - real component of horizontal transport due to mass transport

$V_{\text {mass flux }}$ - imaginary component of horizontal transport due to mass transport

We then updated the governing equations for continuity and transport in SLOSH to include wave stresses and our calculated horizontal transport due to mass flux. First, the new continuity equation (Eq. 2-16) becomes a relationship between the time rate of change of the sea level and the divergence of both the mean current transport (the first and second terms on the right-hand-side of Eq. 2-16) and mass flux transport (the remaining terms on the right-hand-side of Eq. 2-16) (Sмiтн, 2006). The new versions of the the transport equations (Eqs. 2-8 and 2-9) appear below as Eqs. 2-17 and 2-18, respectively. Wave stresses were essentially added as additional wind shear stresses. The mass flux transport was then introduced using the methodology from Sмiтн (2006) to account for the fact that mass flux lost from the waves appears at the mean flow speed, not with zero velocity. The wave stress and mass flux transport inputs were interpolated to the image plane on the SLOSH computational grid. 


$$
\begin{gathered}
\frac{\partial \zeta}{\partial t}=-\frac{\partial U}{\partial x}-\frac{\partial V}{\partial y}-\frac{\partial U_{\text {mass flux }}}{\partial x}-\frac{\partial V_{\text {mass flux }}}{\partial y} \\
\frac{\partial U}{\partial t}=-g(h+\zeta)\left[B_{r} \frac{\partial\left(\zeta-\zeta_{0}\right)}{\partial x}+B_{i} \frac{\partial\left(\zeta-\zeta_{0}\right)}{\partial y}\right]+f\left(A_{r} V+A_{i} U\right) \\
+C_{r}\left(\tau_{x}+\tau_{w x}\right)-C_{i}\left(\tau_{y}+\tau_{w y}\right)-\frac{U}{(h+\zeta)}\left[\frac{\partial U_{\text {mass flux }}}{\partial x}+\frac{\partial V_{\text {mass flux }}}{\partial y}\right] \\
\frac{\partial V}{\partial t}=-g(h+\zeta)\left[B_{r} \frac{\partial\left(\zeta-\zeta_{0}\right)}{\partial y}+B_{i} \frac{\partial\left(\zeta-\zeta_{0}\right)}{\partial x}\right]+f\left(A_{r} U+A_{i} V\right) \\
+C_{r}\left(\tau_{y}+\tau_{w y}\right)+C_{i}\left(\tau_{x}+\tau_{w x}\right)-\frac{V}{(h+\zeta)}\left[\frac{\partial V_{\text {mass flux }}}{\partial x}+\frac{\partial U_{\text {mass flux }}}{\partial y}\right]
\end{gathered}
$$

Where: $\tau_{\mathrm{wx}},-$ real wave radiation stress per unit mass component

$\tau_{\mathrm{wy}}-$ imaginary wave radiation stress per unit mass component 


\section{CHAPTER 3}

\section{RESULTS}

\subsection{WAVE SET-UP AND MASS FLUX FORCING}

We completed testing of three different hurricane simulations, each with three different forcing options as follows: 1. wind stress only (SLOSH unchanged); 2. wind stress with wave set-up effects; and 3. wind stress with both wave set-up and mass flux effects. Two of the hurricanes (a Category 1 and 4) were tested on the SLOSH model's ETPA basin; a simulation of Hurricane Andrew was run on the HMIA basin. The storm tide for the latter two forcing options are dependent on the wave fields determined from running the SWAN third-generation wave model on the wind-stress-only results from SLOSH. The wave characteristics detailed in Section 2.3 were of greatest importance. Figure 3-1 shows the contours of the maximum significant

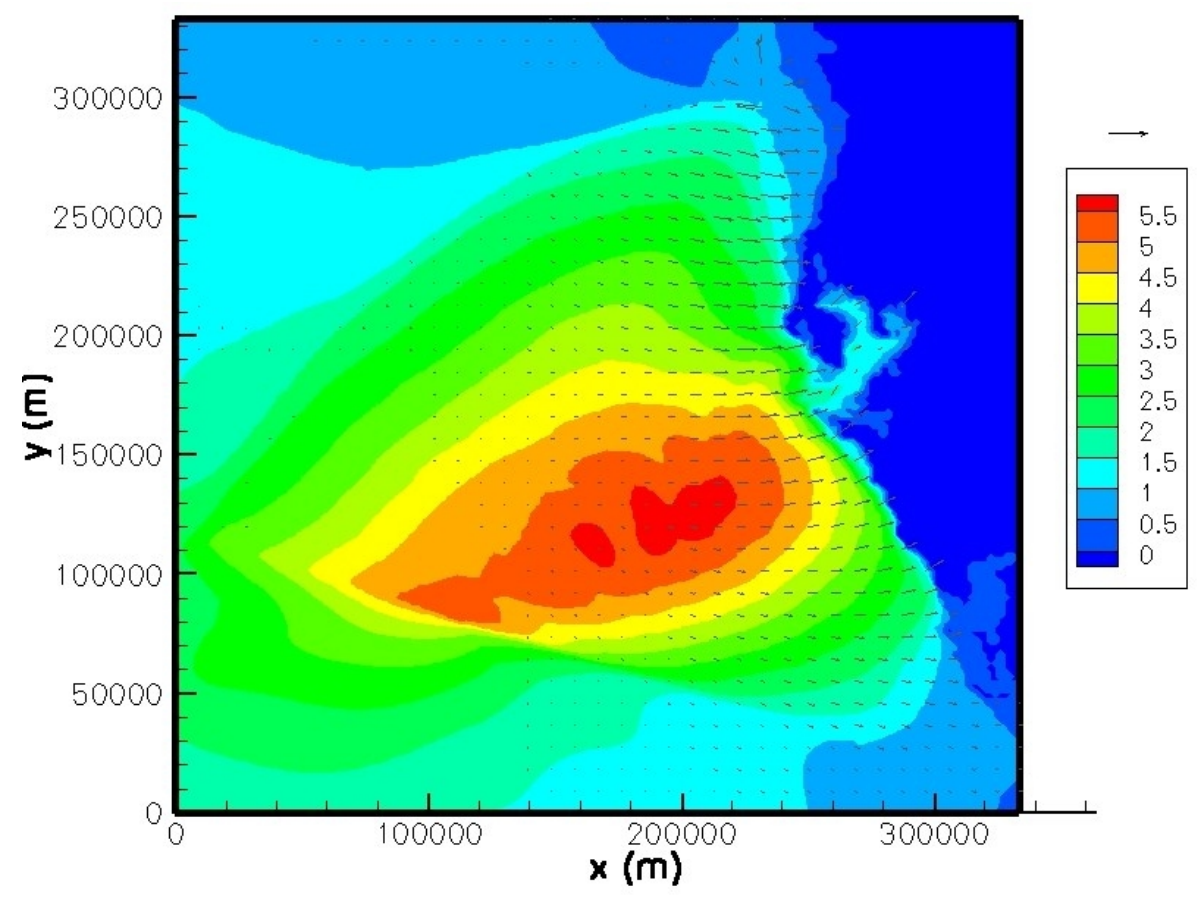

Figure 3-1: Maximum significant wave height contours with mass flux velocity vectors from Category 1 hurricane simulation over Tampa Bay on the SWAN Cartesian grid. The contours shown vary from $0 \mathrm{~m}$ (on land) to $5.66 \mathrm{~m}$ (in the Gulf). The mass flux velocities vary from 0 $\mathrm{cm} / \mathrm{s}$ to $61 \mathrm{~cm} / \mathrm{s}$. The reference vector shown represents a velocity of $1 \mathrm{~m} / \mathrm{s}$. 
wave heights for the Category 1 storm with vectors for the maximum mass flux velocities superimposed. The maximum significant wave heights occur in the open Gulf, topping out at $5.66 \mathrm{~m}$. As the waves travel toward the shore, larger waves loose energy from interactions with the sea bed and break farther from the shoreline. This pattern of successive breaking by wave height is clearly evident in Figure 3-1. In both hurricane simulations over Tampa Bay, as well as Andrew in the Atlantic, the maximum wave heights have the same spatial pattern. The Category 4 hurricane caused larger maximum significant wave heights (up to $11.48 \mathrm{~m}$ ), although these maximums were closer to the ETPA basin deep water boundary. Hence, a 75 percent increase in the maximum wind parameter led to over a doubling of the maximum wave heights. Hurricane Andrew caused maximum significant waves of $7.67 \mathrm{~m}$ beyond the continental shelf off of Miami. The maximum flux velocity vectors shown on Figure 3-1 are intrinsically linked to the maximum significant wave heights, since wave flux velocities vary as a square of the wave height over the same depth contours (Eq. 1-2). This relationship explains why the maximum velocities from the Category 4 simulation were $93 \%$ greater than the Category 1 storm $(1.18 \mathrm{~m} / \mathrm{s}$ versus $0.61 \mathrm{~m} / \mathrm{s}$ ). Both tests showed very similar spatial distributions of mass flux velocities; the greatest values were found between the coast and $100 \mathrm{~km}$ offshore. Hurricane Andrew yielded a maximum mass flux velocity of $0.86 \mathrm{~m} / \mathrm{s}$. In all three cases, the mass flux velocity vectors are nearly perpendicular to the shoreline in the surf zone, leading to the maximum transfer of momentum to the water column. Wave stresses (Eqs. 2-13 and 2-14) were also obtained from SWAN in each simulation. Figure 3-2 shows the maximum wave stress values for the Category 1 simulation over Tampa Bay. For reasons explained in Section 1.1.2, the maximum forces occur near the shoreline where hurricane-induced waves shoal and break, imparting their energy to the water column. The maximum wave stress was $1.14 \mathrm{~N} / \mathrm{m}^{2}$, but most nearshore stresses range between 0.5 and $0.7 \mathrm{~N} / \mathrm{m}^{2}$. Like wave height and mass flux velocities, the maximum 


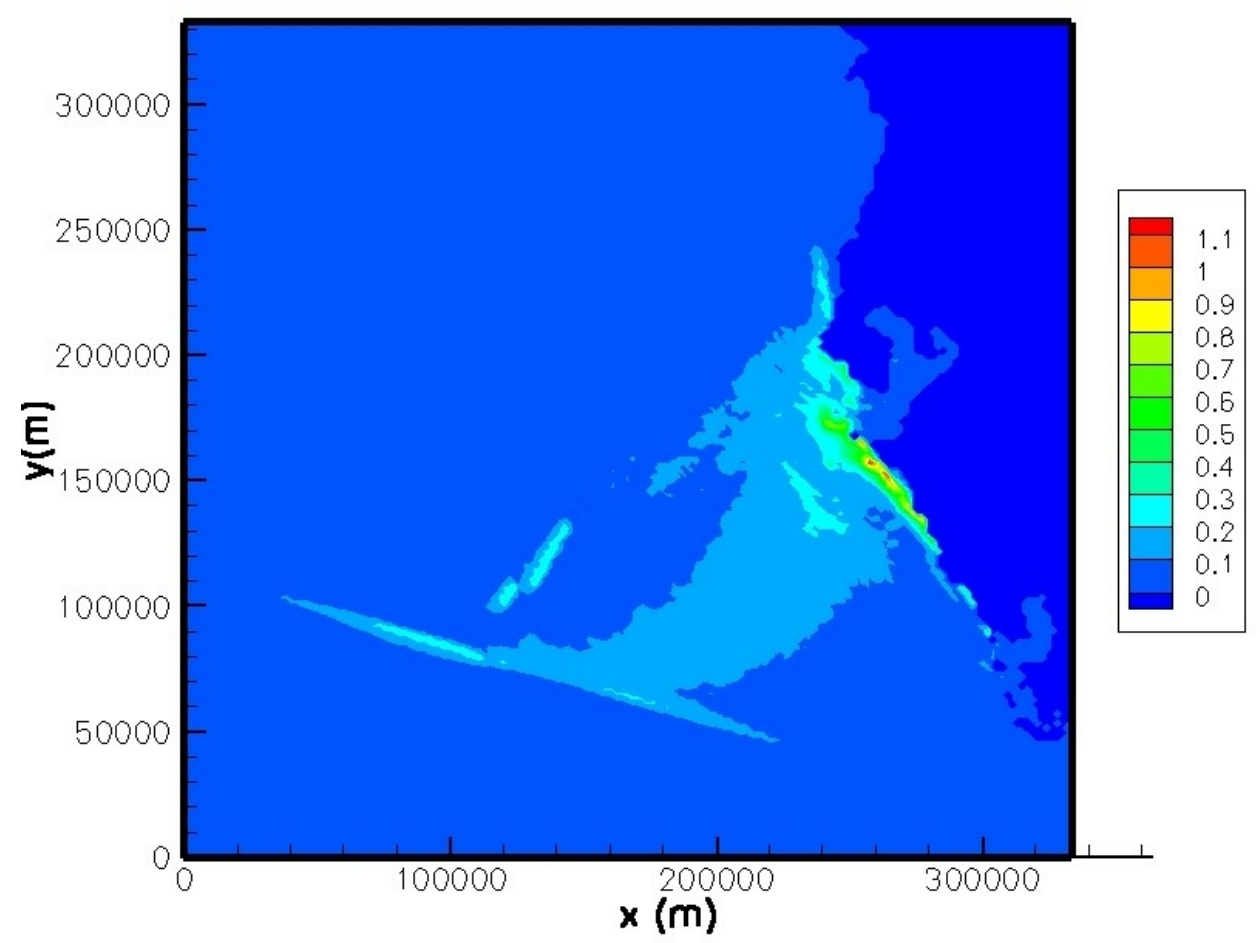

Figure 3-2: Maximum wave-induced stress contours from Category 1 hurricane simulation over Tampa Bay. The maximum stresses range between 0.0 and $1.14 \mathrm{~N} / \mathrm{m}^{2}$. The highest maximum stresses occur nearshore where hurricane-induced waves shoal and break, imparting their momentum into the water column.

wave stresses from the Category 4 storm share a similar spatial distribution but differ in magnitude. The Category 4 storm sees maximum stress values of $1.57 \mathrm{~N} / \mathrm{m}^{2}$; Hurricane Andrew's maximum wave stresses also occur near the coast and top $5.45 \mathrm{~N} / \mathrm{m}^{2}$.

\subsection{SPATIAL RESULTS}

We analyzed the spatial variability of the storm tide due to different forcing by looking at the results in three ways. First we examined the maximum storm tide levels over the entire domain. This method is perhaps the most apparent since the SLOSH model was designed to provide ENV files with the maximum water levels computed at each grid point. The second analysis looks at maximum storm surges incurred at chosen points. Finally we compared both the maximum and average overland surge values and number of inundated points in each forcing 
case. This final analysis targets the most practically relevant question: to what extent does each forcing component impact storm surge levels overland?

\subsubsection{Maximum Storm Tide Levels}

We determined domain-wide maximum storm tide levels for each storm simulation and for three forcing options: A) wind stress only; B) wind and wave stresses; and C) wind and wave stresses with mass flux transport. Table 3-1 shows the maximum surge level in each simulation. The greatest surges occur in the Category 4 hurricane, followed by Hurricane Andrew and finally the Category 1 storm. Mass flux transport nearly doubles the effect of wave stresses in each storm. A domain-wide snapshot (not pictured) shows that the maximum storm tide levels are found in and around Tampa Bay for the Category 1 and 4 hurricanes and Biscayne Bay for Hurricane Andrew. Focusing on the zone of greatest surges, Figure 3-3 shows a zoomed view of the Bay and surrounding coastline for the Category 1 simulation. We see a clear increase in maximum storm surge levels with the addition of each forcing component. Wind-only forcing levels range from about $1.0 \mathrm{~m}-2.0 \mathrm{~m}$, wind and wave forcing yield a range of $1.25 \mathrm{~m}-2.25 \mathrm{~m}$, and the addition of mass flux raises the range from $1.75 \mathrm{~m}-2.35 \mathrm{~m}$. Similar spatial patterns are observed with the other two storm simulations.

Table 3-1: Domain-wide maximum storm tide levels (m) calculated for each simulation. Percent difference from wind stress only case appears in parentheses.

\begin{tabular}{llll}
\hline $\begin{array}{l}\text { Storm } \\
\text { Simulation }\end{array}$ & Wind-Stress Only & Wind and Wave Stress & $\begin{array}{l}\text { Wind and Wave Stresses } \\
\text { with Mass Flux }\end{array}$ \\
\hline Cat1-Tampa & 2.14 & $2.23(4 \%)$ & $2.35(10 \%)$ \\
Cat4-Tampa & 5.33 & $5.83(9 \%)$ & $6.19(16 \%)$ \\
Andrew & 4.00 & $4.40(10 \%)$ & $4.59(15 \%)$ \\
\hline
\end{tabular}



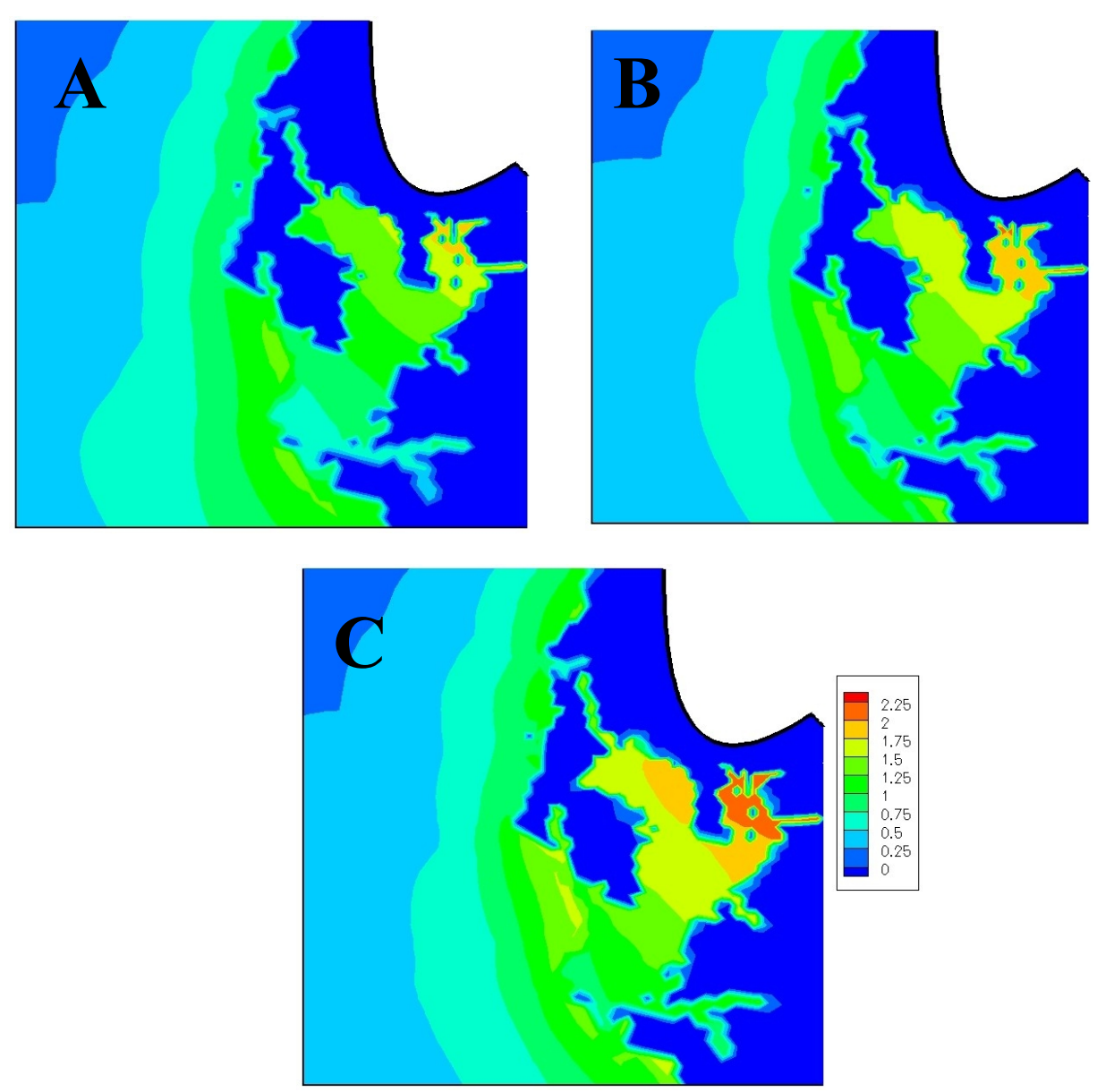

Figure 3-3: Zoomed view of maximum storm tide levels from three Category 1 hurricane simulations over Tampa Bay: A) Wind-stress only; B) Wind-stress and wave set-up; and C) Wind-stress, wave set-up, and mass flux effects. The contours show storm tide levels in meters, as shown in the legend.

We can take this analysis a step further by first plotting the differences between the forcing options. It would be useful to look at these results both as a positive or negative change in height and also as a percent difference. Figure 3-4 contrasts the maximum surge levels with and without wave set-up effects for the Category 1 storm over Tampa Bay. Figure 3-4A shows the difference in meters, whereas Figure 3-4B shows the absolute difference in percent. Figure 3-5 shows the differences when mass flux transport is also included in the forcing. Again, Figure 3-5A shows the difference in meters and Figure 3-5B shows the absolute percent difference. Both of these figures show that wave forcing has two main impacts on storm surge levels. A 


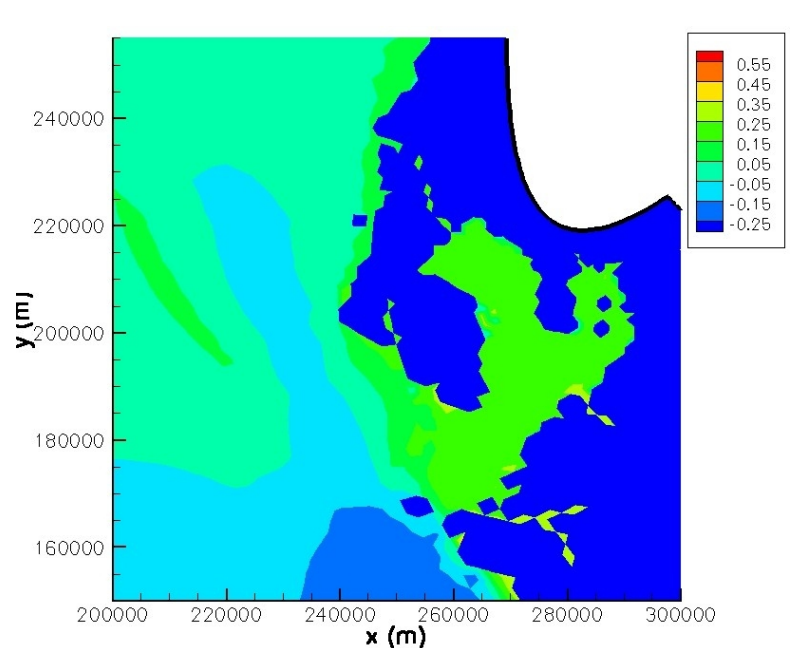

$\mathbf{A}$

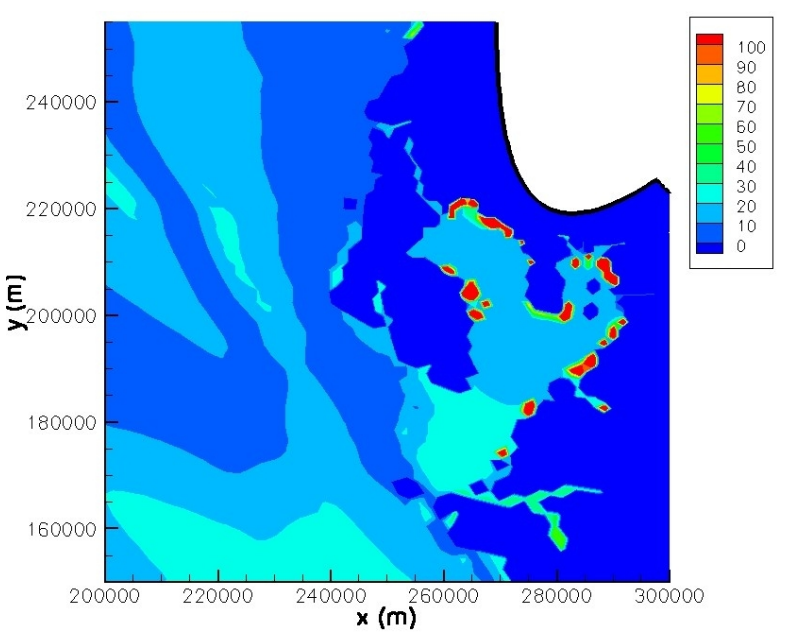

B

Figure 3-4: Comparison of maximum storm tide levels for Category 1 hurricane simulations using wind stress only and wave set-up with mass flux and wind stress. Figure A shows the contours of the height differential in meters. Note that the darkest blue values are actually dry points for the wind stress only case. Figure B shows the contours of the height differential as percent difference.

decrease in surge is evident in the open Gulf, whereas the surge within the Bay clearly rises.

Both of these results are completely consistent with the theory of wave set-up presented in

Section 1.1.2. As the waves form and propagate, they gain momentum, lowering the mean sea elevation. As the waves approach the shallows, they break and impart their momentum to the water column. This transfer of momentum is responsible for the rise in surge levels. We can see that the greatest percent differences occur at the Bay's shoreline, where numerous points experience over a 100 percent increase in surge levels. The Bay itself generally experiences between a 10 and 20 percent increase for both wave forcing cases.

From historical comparisons, SLOSH has an accepted error of \pm 20 percent for its maximum storm surge calculations (JELESNIANSKi et al, 1992). We examined our data to determine how many points fell outside of this error range when wave effects were included. If a majority of points were inside this envelope, then the net effect of neglecting waves would be on the same magnitude as the other model assumptions, and, thus, inconsequential. However, 


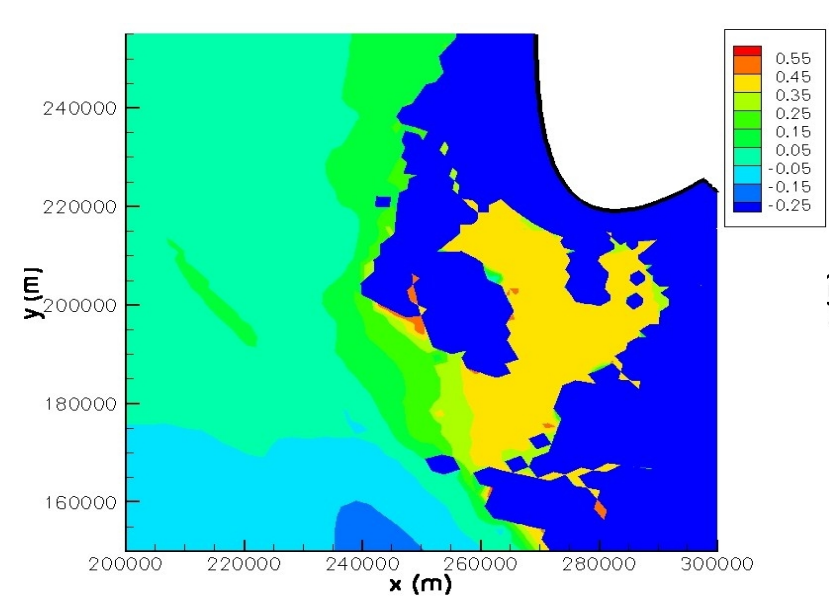

A

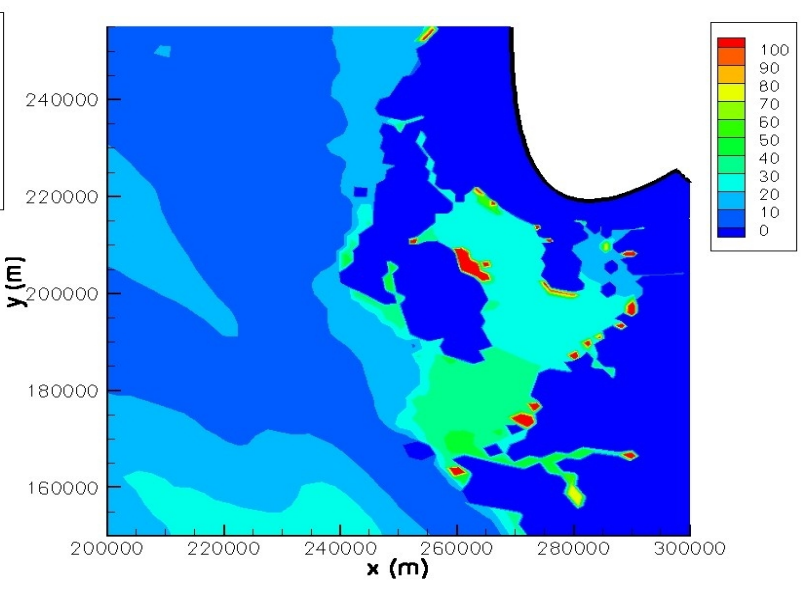

B

Figure 3-5: Comparison of maximum storm tide levels for Category 1 hurricane simulations using wind stress only and wave set-up with wind stress. Figure A shows the contours of the height differential in meters. Note that the darkest blue values are actually dry points for the wind stress only case. Figure B shows the contours of the height differential as percent difference.

numerous "extreme" points emerged (Table 3-2). Only one case (Hurricane Andrew with only wind and wave stresses) resulted in less than ten percent of the inundated points experiencing changes outside the \pm 20 percent range. For the Tampa Bay storms, at least 23 percent of the points were outside the error for the four wave forcing simulations. Yet, these results do not infer universal storm surge rise. In fact, less than half of the "extreme" points experienced increased surge. Figure 3-6 is a histogram of the percent difference between A) wave and wind stress and

Table 3-2: Storm surge levels outside the SLOSH error envelope for each storm simulation.

\begin{tabular}{llllll}
\hline \multirow{2}{*}{$\begin{array}{l}\text { Storm } \\
\text { Simulation }\end{array}$} & $\begin{array}{l}\text { Total Inundated } \\
\text { Points (Wind-Stress } \\
\text { Only) }\end{array}$ & \multicolumn{2}{l}{$\begin{array}{l}\text { Number of Points Recording } \\
\text { Higher Maximum Surges }\end{array}$} & \multicolumn{2}{l}{$\begin{array}{l}\text { Points Outside } \pm 20 \% \\
\text { Range }(+20 \%)\end{array}$} \\
\cline { 3 - 6 } & Wave Set-up & Mass Flux & Wave Set-up & Mass Flux \\
\hline Cat1-Tampa & 6903 & 3066 & 3403 & $1678(266)$ & $1592(640)$ \\
Cat4-Tampa & 7267 & 3497 & 3754 & $2848(673)$ & $3131(1106)$ \\
Andrew & 13397 & 11897 & 12827 & $841(792)$ & $2062(2015)$ \\
\hline
\end{tabular}



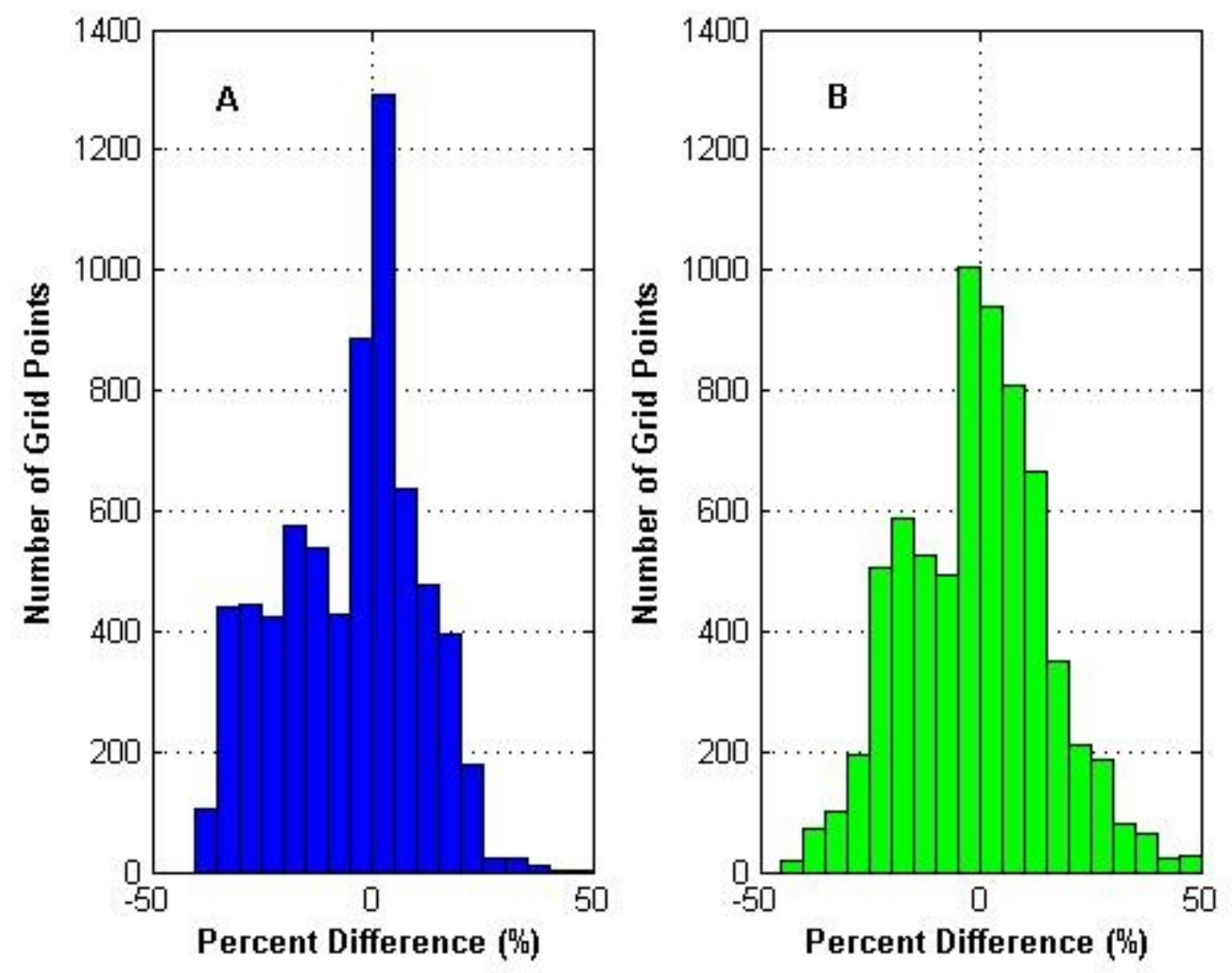

Figure 3-6: Percent difference histogram between A) wave set-up and wind stress only and B) wave set-up with mass flux and wind stress only for a Category 1 hurricane simulation over Tampa Bay. Each bin represents five percent. Note than in both cases there are a small number of points with greater than +50 percent difference.

wind stress only and B) wave and wind stresses with mass flux and wind stress only for the Category 1 hurricane. For the former case, most points show a decrease in storm surge levels, whereas the latter case is more balanced. Although this result seemingly contradicts the maximum storm surge plots, two key points must be mentioned. First, almost all of the points that experience smaller surge values are found in the open Gulf where wave set-down occurs. Second, this analysis does not account for points that become inundated only during wave forcing simulations (see Section 3.3.3). 


\subsubsection{Selected Points Analysis}

We selected four points in each basin to perform individual spatial and temporal analysis. These points and their coordinates are listed in Table 3-3. We chose an additional point in the HMIA basin (6042) because it corresponds to the location of Burger King Headquarters on SW $184^{\text {th }}$ Street in Miami, Florida, site of the maximum recorded storm surge level during Hurricane Andrew (16.9 feet or $5.2 \mathrm{~m})$. The other points were selected as sites of interests because they were located near the coast and/or showed a significant change in the domain-wide comparisons.

Table 3-3: Coordinates and location description for grid points selected for spatial and temporal analysis.

\begin{tabular}{lcccc}
\hline Basin & Point ID & Longitude $\left({ }^{\circ} \mathrm{W}\right)$ & Latitude $\left({ }^{\circ} \mathrm{N}\right)$ & Description \\
\hline ETPA & 2452 & 82.4216 & 27.6746 & Middle of Tampa Bay \\
ETPA & 2984 & 82.5335 & 27.7772 & Tampa Bay eastern shoreline \\
ETPA & 4253 & 82.6429 & 27.4916 & South side of Tampa Bay \\
ETPA & 5143 & 82.4979 & 27.2597 & Gulf coast between Venice and Sarasota \\
\hline HMIA & 2700 & 80.5400 & 25.2999 & Atlantic coast south of Biscayne Bay \\
HMIA & 6042 & 80.3118 & 25.6062 & Burger King Headquarters in Miami \\
HMIA & 6788 & 80.2885 & 25.6440 & Biscayne Bay western shoreline \\
HMIA & 8551 & 80.1477 & 25.6344 & North side of Biscayne Bay \\
HMIA & 11408 & 80.1695 & 25.8240 & Atlantic coast north of Biscayne Bay \\
\hline
\end{tabular}

First, we can analyze the maximum storm surge levels computed at each of these points for all the simulations run on their respective grids, as depicted in Figure 3-7. From these results we can see a general trend emerge: storm surge levels increase with each additional wave forcing component. Neglecting the points 5143 and 2700, which were chosen specifically for their 
negative-trend irregularity, we arrive at an average increase in storm surge of 25 percent from wave stresses and 29 percent from mass flux. However, this trend is by no means universal. In the HMIA basin, point 6788 records its highest surge level with wave and wind stresses only and point 2700 sees its greatest surge when only wind forcing is active. These results by location show that the interaction between the wind and wave forcing is complex; indeed, wind and wave forcing at times work in tandem, but also against one another based on wind and bathymetric characteristics. Moreover, the individual wave components also share a similar nonlinear relationship. Like the domain-wide analysis of maximum surge levels, however, we sill neglect those overland points that become inundated with each successive addition of wave forcing.
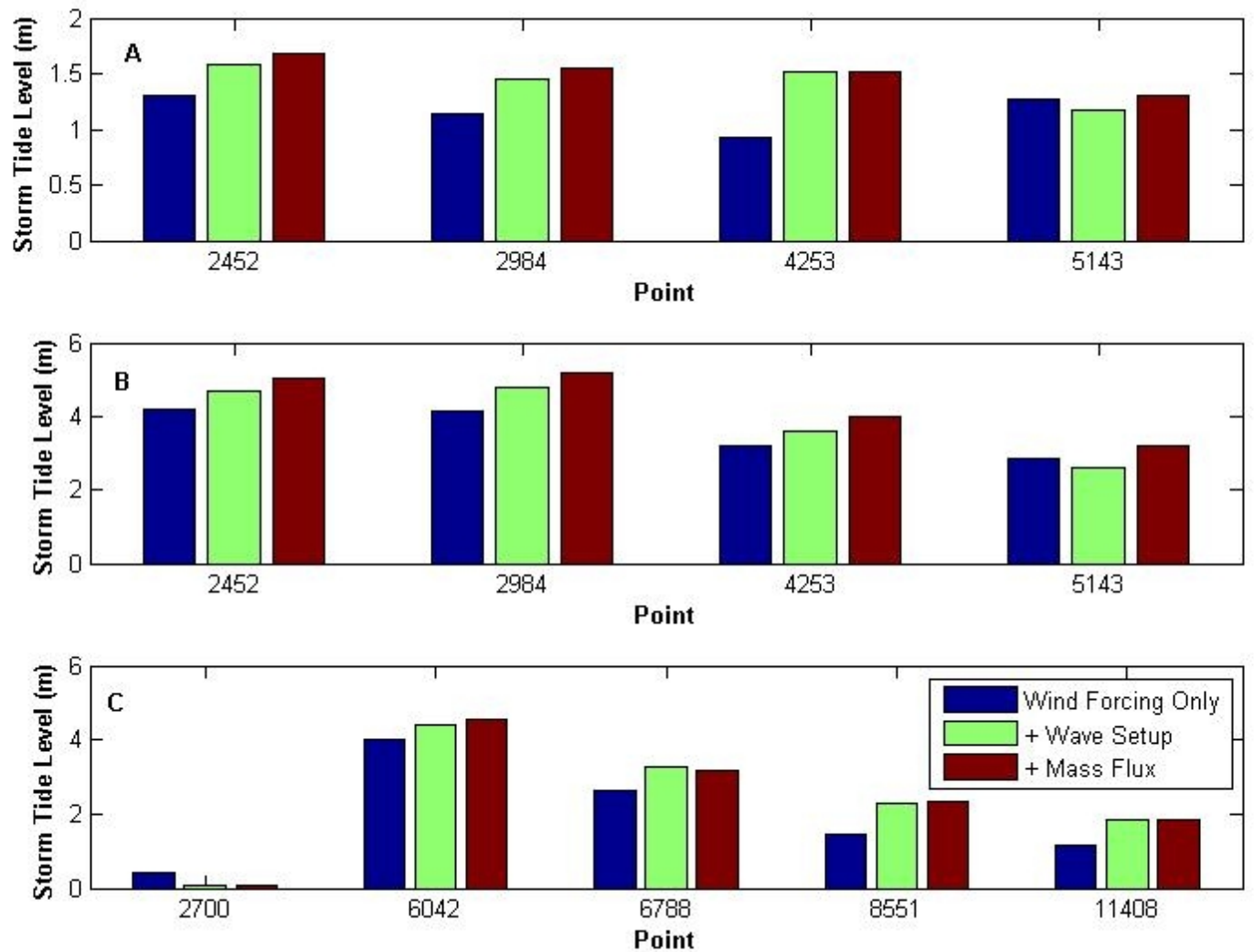

Figure 3-7: Maximum storm tide levels (m) at selected points for A) Category 1 simulation over Tampa Bay, B) Category 4 simulation over Tampa Bay, and C) Hurricane Andrew simulation over Miami. 


\subsubsection{Overland Inundation}

An assessment of overland inundation data would perhaps be more meaningful than assessment of the total inundation shown over the entire domain or maximum surge levels at selected points since it focuses on the essence of storm surge modeling - predicting surge incurred by coastal inhabitants and infrastructure. Here we examine only the land grid points in either SLOSH basin (those with an elevation greater than the mean sea level, $0 \mathrm{~m}$ ). This approach allows us to see how much land becomes inundated in each case, and to what degree. Since the minimum spacing of the ETPA and HMIA grids is about two kilometers, we can approximate every inundated point as an additional four square kilometers of coastal flooding. The results from the nine simulations appear in Table 3-4. For the Category 1 storm, the addition of wave stresses led to a 24 percent increase in surge levels over nearly twice as many grid locations. The extra addition of mass flux only increased the number of flooded points by 15 percent, while the average surge level rose to 35 percent greater than the wind-only case. Figure 3-8 shows the spatial distribution of the overland surge due to the Category 1 hurricane. Figure $3-8 \mathrm{~B}$ reveals that most of the new inundation from wave stresses occurs around the Bay, while Figure 3-8C shows only a rise in surge levels when mass flux is considered. Topography is sure to play a vital role in determining what proportion of the additional surge from wave forcing inundates further onto land or piles higher at the same locations.

The overland surge results for the Category 4 hurricane and Hurricane Andrew bare a striking similarity - almost identical percent increases in average surge levels for both wave forcing cases. This suggests that overland inundation is more closely linked the the storm's strength than coastal bathymetry. 
Table 3-4: Overland average surge results for all test storms and forcing options.

\begin{tabular}{|c|c|c|c|c|c|}
\hline Storm & Forcing & $\begin{array}{l}\text { Average } \\
\text { Maximum }\end{array}$ & $\begin{array}{l}\text { Number of } \\
\text { Inundated }\end{array}$ & $\begin{array}{l}\text { Difference from } \\
\text { Wind Stress Only }\end{array}$ & $\begin{array}{l}\text { Difference from } \\
\text { Wind Stress }\end{array}$ \\
\hline \multirow[t]{2}{*}{ Simulation } & & Overland & "Dry" Points & Case (m) & Only Case (\%) \\
\hline & & Surge (m) & & & \\
\hline Cat1-Tampa & Wind Stress & 1.22 & 52 & -- & -- \\
\hline \multirow[t]{2}{*}{ Cat1-Tampa } & Wind \& Wave & 1.52 & 96 & 0.30 & 25 \\
\hline & Stress & & & & \\
\hline \multirow[t]{3}{*}{ Cat1-Tampa } & Wind \& Wave & 1.65 & 110 & 0.43 & 35 \\
\hline & Stress with & & & & \\
\hline & Mass Flux & & & & \\
\hline Cat4-Tampa & Wind Stress & 4.27 & 417 & -- & -- \\
\hline \multirow[t]{2}{*}{ Cat4-Tampa } & Wind \& Wave & 4.75 & 486 & 0.48 & 11 \\
\hline & Stress & & & & \\
\hline \multirow[t]{3}{*}{ Cat4-Tampa } & Wind \& Wave & 5.04 & 535 & 0.77 & 18 \\
\hline & Stress with & & & & \\
\hline & Mass Flux & & & & \\
\hline Andrew & Wind Stress & 1.89 & 639 & -- & -- \\
\hline \multirow[t]{2}{*}{ Andrew } & Wind \& Wave & 2.07 & 721 & 0.18 & 10 \\
\hline & Stress & & & & \\
\hline \multirow[t]{3}{*}{ Andrew } & Wind \& Wave & 2.22 & 1076 & 0.33 & 17 \\
\hline & Stress with & & & & \\
\hline & Mass Flux & & & & \\
\hline
\end{tabular}




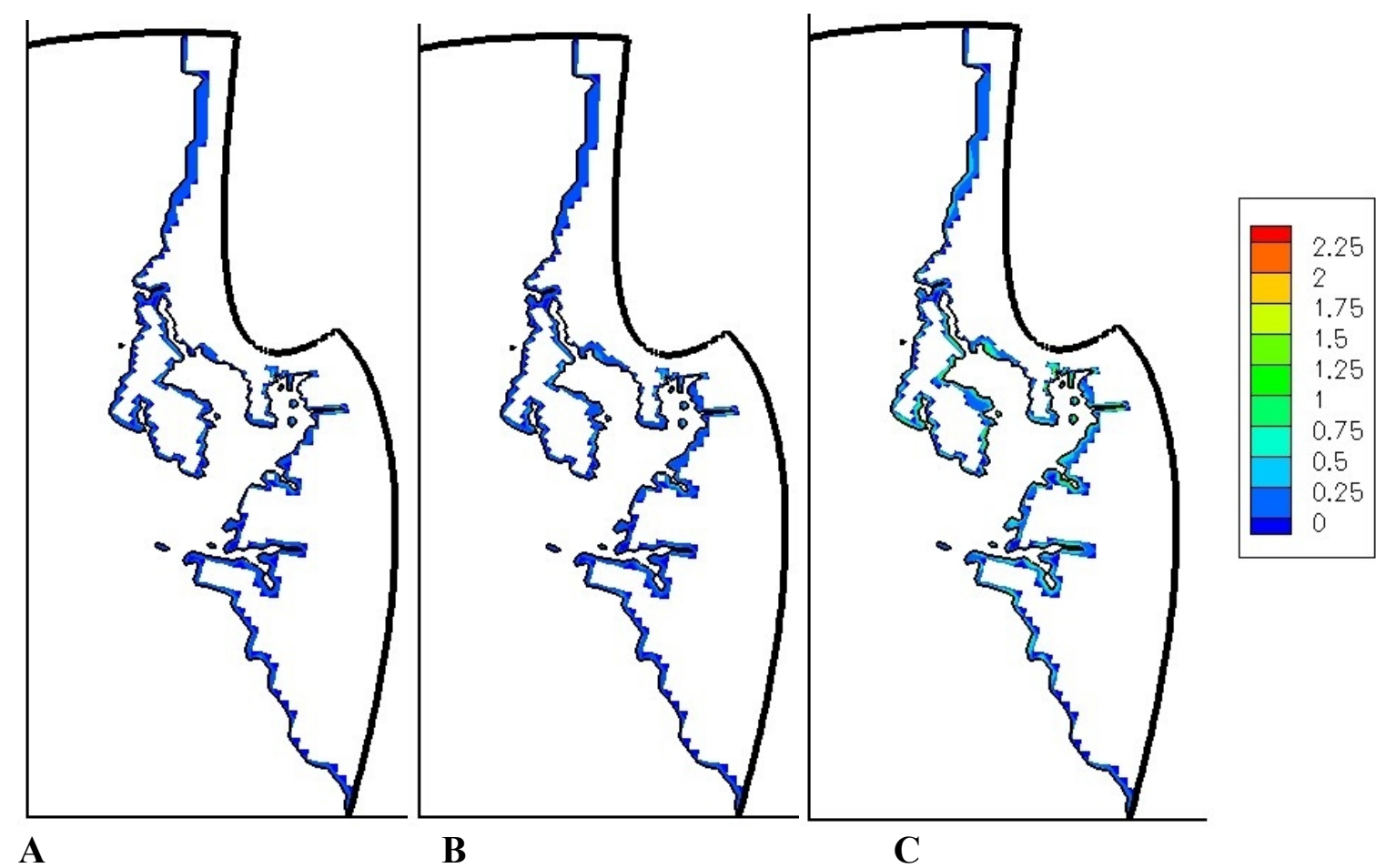

Figure 3-8: Contours of overland storm tide levels (m) for three simulations of a Category 1 hurricane over Tampa Bay: A) Wind stress only; B) Wave and wind stress; and C) Wave and wind stress with mass flux.

\subsection{TEMPORAL RESULTS}

We have so far explored the spatial variations in storm surge for the nine simulations. We will now examine the temporal variations in storm tide levels the same three ways: domain-wide maximum surges, analysis of selected points, and overland inundation.

\subsubsection{Maximum Storm Tide Levels}

The first temporal analysis is a comparison of the maximum surge level due to each forcing option at given time increments during the three storms. The results are shown in Figure 3-9. Looking first at the Tampa Bay simulations (Figure 3-9A and 3-9B), we can see that the three forcing options record similar maximum surges during the first 6 hours of the storm duration, with slightly lower levels for the wave and wind stress case around the $4^{\text {th }}$ hour. This 
result coincides with theory; as the hurricane is located far offshore, waves have not yet arrived at the coast, and those that have formed cause set-down in deep water. Hence, wave set-up (through breaking) and mass flux transport have minimal to no influence. As the storm nears the coast and makes landfall north of Tampa Bay (between 6 hours and 12 hours), the three series diverge. Maximum surge levels increase to their apexes during this period, with each additional wave forcing component yielding higher maximum surges (except for another slight decrease in levels from wave stresses again due to set-down). Surge waters then recede for the rest of the duration, lowering surge levels in each case.
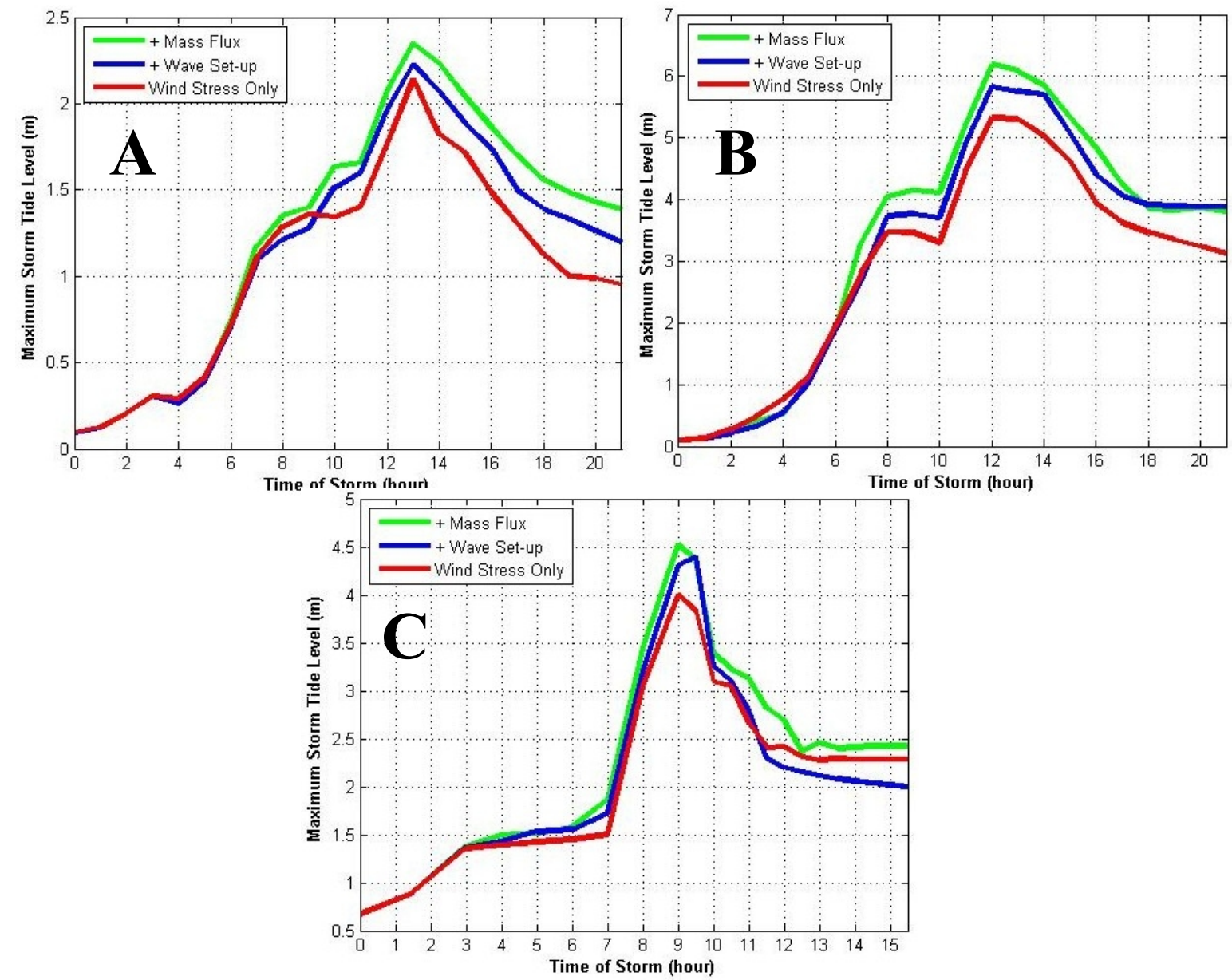

Figure 3-9: Maximum storm tide levels recorded for three forcing options through the storm's duration during the following simulations: A) Category 1 on ETPA basin; B) Category 4 on ETPA basin; and C) Hurricane Andrew on HMIA basin. 
For the Hurricane Andrew simulation (Figure 3-9C), a nearly identical pattern emerges. Maximum surge levels for all three forcing cases occur around landfall. Interestingly, after the storm has moved onto land, the wave stresses lower maximum surge below wind-stress-only levels. Most likely, this depreciation can be attributed to offshore-directed winds forming waves that produce a set-down in the water column.

\subsubsection{Selected Points Analysis}

Using the same points listed in Table 3-3, we can analyze the time series progression of surge levels at independent positions throughout each domain and determine if each site sees the same general trend that the domain-wide maximum levels follow. The first position of interest is point 2984 in the ETPA basin. This point corresponds to a location just off the eastern shoreline

of Tampa Bay. We will look at the hourly surge levels from both the Category 1 and 4 hurricanes at this site. Figure 3-10 shows the results for each forcing case for the Category 1 storm. Like the domain-wide results, the profiles show remarkable agreement for the first 10 hours of the storm. Surge levels decrease as wind is blowing down the area; wave effects have yet to extend into the Bay. Surge levels then steeply increase in each case, reaching their maximums in the $15^{\text {th }}$ to $16^{\text {th }}$ hour of the storm. Interestingly, these maximum levels occur nearly four hours after the storm's landfall, demonstrating that surge generated from both wind and waves does not reach the shore instantaneously. Wave set-up effects do reach the location slightly faster than the wind stress effects, a finding supported by other studies (WeAver, 2004). The mass flux profile appears to be a composite of the wind-stress-only and wave-and-wind-stress profiles; it has the same general shape as the wind stress case, but has levels slightly higher than the wave-andwind-stress scenario. 


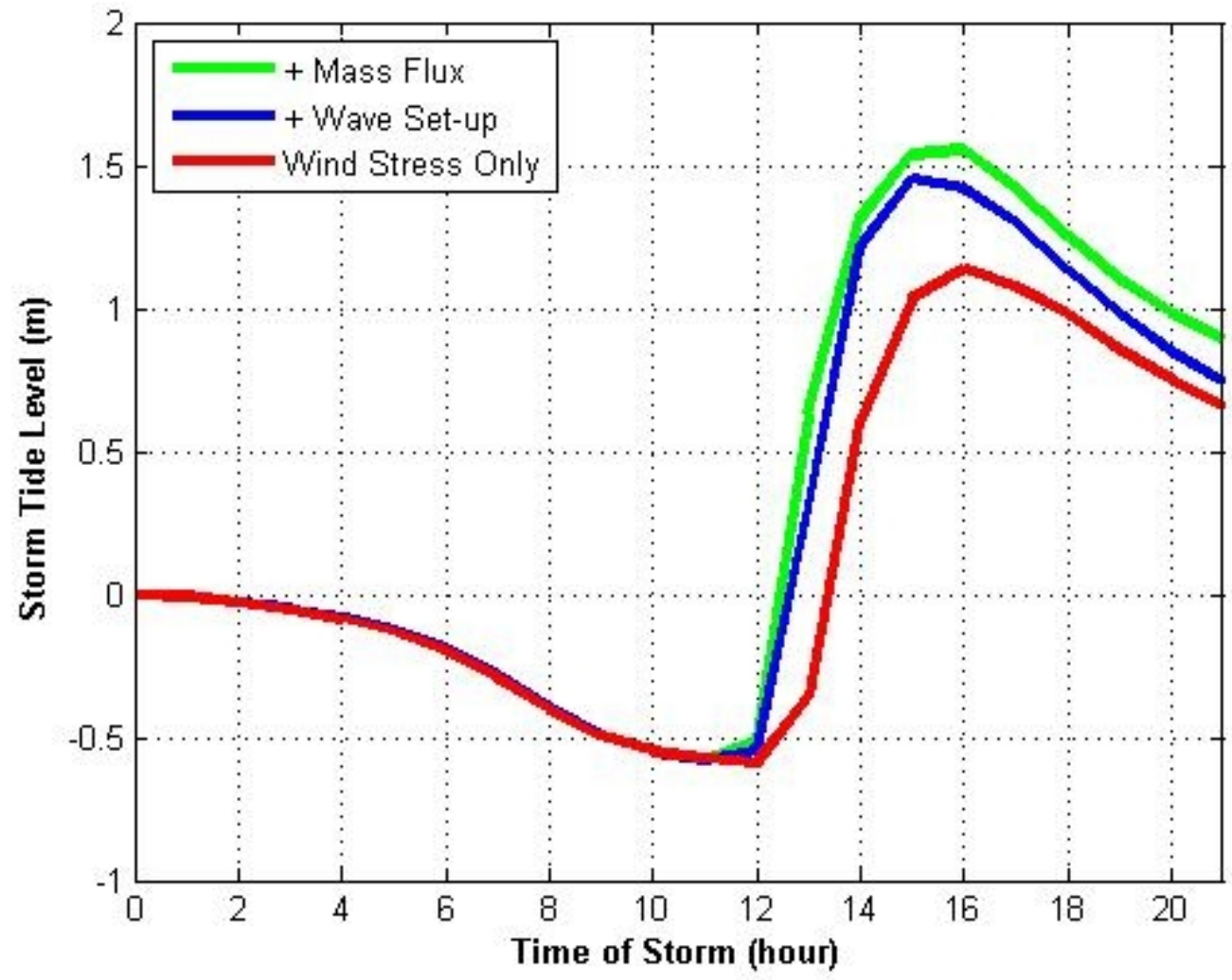

Figure 3-10: Hourly surge levels at point 2984 in the ETPA basin for Category 1 hurricane simulations of each forcing option. This point is located just off the eastern shoreline of Tampa Bay.

We can see that the Category 4 simulation yielded very similar results (Figure 3-11). Again, the profiles considerably agree over the first 10 hours of the storm before diverging. Maximum surges are reached two hours earlier than in the Category 1 simulation, however, since the stronger storm produces higher period waves that travel faster. The overall accord between the Category 1 and 4 time series implies that storm surge evolution is not strongly dependent on the strength of the hurricane. Conversely, maximum surge levels are indeed heavily influenced by a storm's magnitude, a result clearly evident in all of the results presented. 


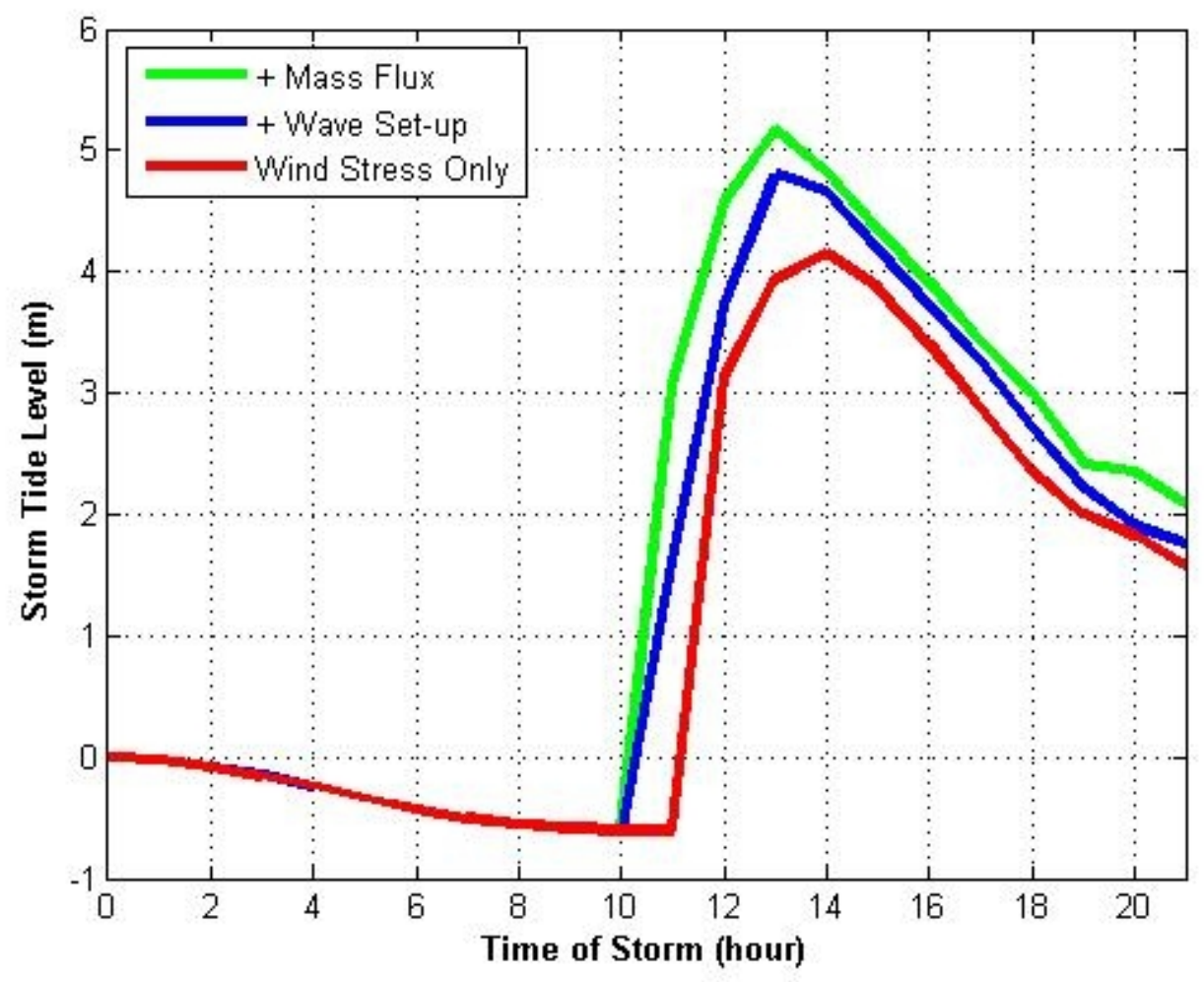

Figure 3-11: Hourly surge levels at point 2984 in the ETPA basin for Category 4 hurricane simulations of each forcing option. This point is located just off the eastern shoreline of Tampa Bay.

At another site in the ETPA basin, point 5143 located on the Gulf coast between Sarasota and Venice, wave forcing has an opposite effect on surge levels. Figure 3-12 shows the time series profiles for the three Category 1 tests. For the first six hours of the storm, the profiles are nearly identical. From this time to end of the simulation, wave set-up begins to counteract wind stresses and yield lower surge levels. When mass transport is included, surge levels reach the same maximum as wind-only forcing but then also drop below the unedited SLOSH levels. These results prove that wave effects do not automatically lead to higher surge levels at every location, even along the coast. Onshore directed winds blowing as the hurricane passes the point induce wave development, and, thus, wave set-down in the nearshore region, driving water 
elevations lower. Another noteworthy finding at this location is the role of mass flux. Within the Bay, mass flux almost always adds additional surge, especially in the interval of peak surge.

Here, mass flux only alters the surge levels in a narrow two-hour window. Outside of this range, mass transport contributes no positive or negative effects to surge results, showing the location dependence of its effect.

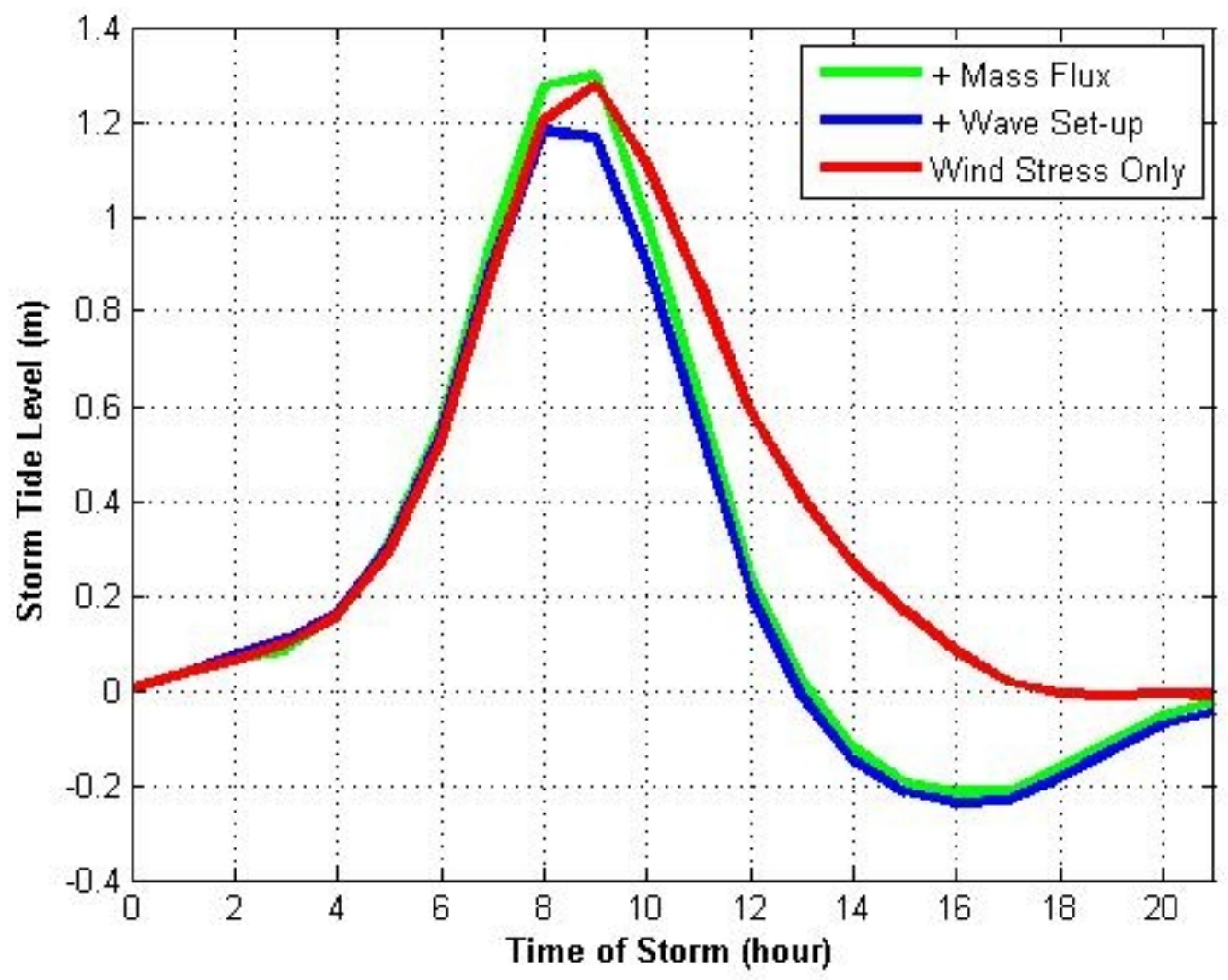

Figure 3-12: Hourly surge levels at point 5143 in the ETPA basin for Category 1 hurricane simulations of each forcing option. This point is located just off the coast between Sarasota and Venice, south of Tampa Bay.

Figure 3-13 shows the surge results at the same point for the Category 4 hurricane tests. Maximum levels are reached approximately an hour earlier, but the same overall trends persist for the wind-only and wave set-up cases. The mass flux simulation veers from the Category 1 trend after the maximum surge is reached. Instead of dropping to meet the wave set-up series, 
the mass flux case remains inundated. Near the end of the storm, the mass flux component raises the sea elevation by around $2 \mathrm{~m}$. A plausible explanation for this discrepancy is that the addition of mass flux caused excessive inland inundation. Hence, as the storm passed, water begins to recede from farther onshore. This process would keep surge levels higher for a longer duration for points along the coastline, such as 5143 .

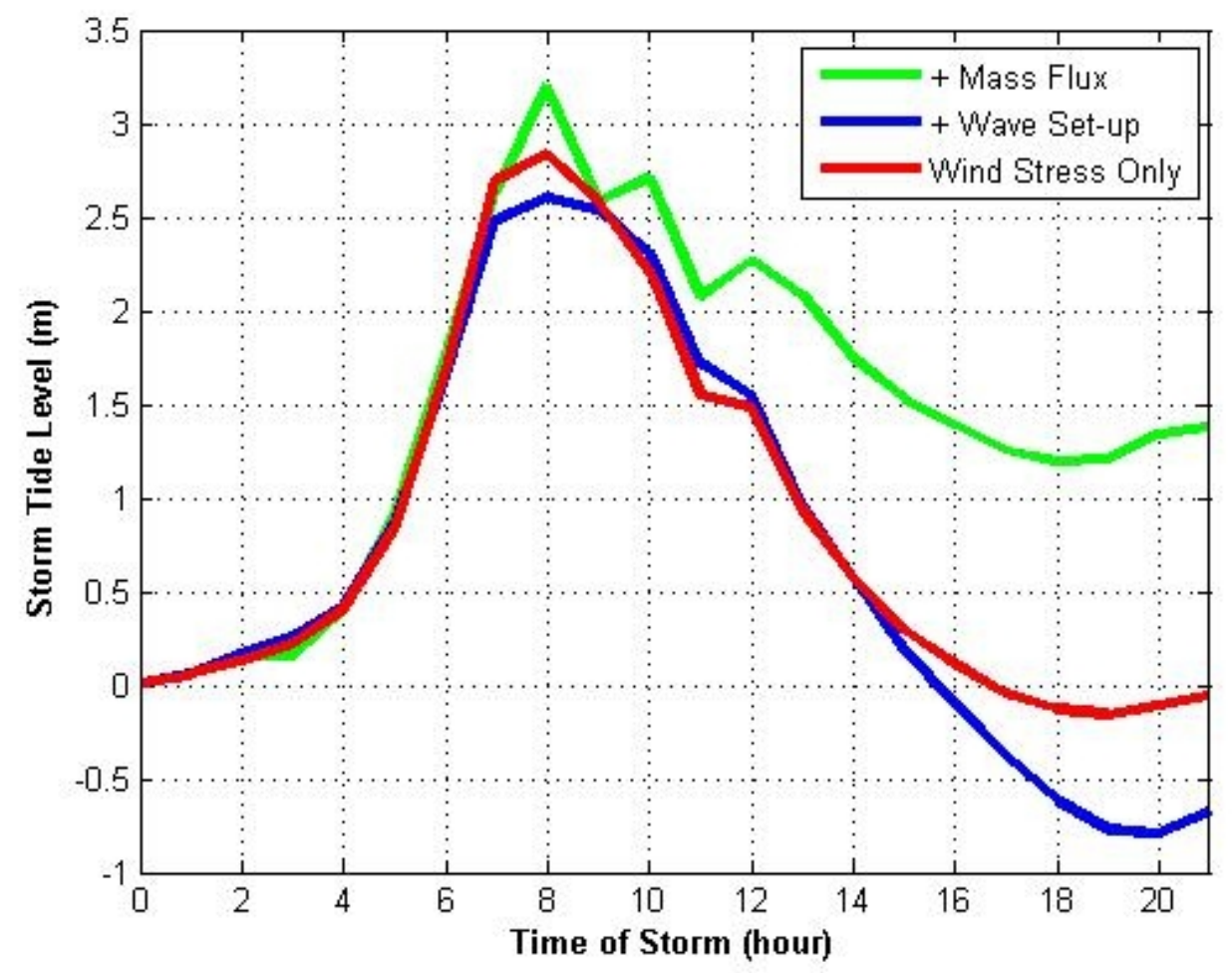

Figure 3-13: Hourly surge levels at point 5143 in the ETPA basin for Category 4 hurricane simulations of each forcing option. This point is located just off the coast between Sarasota and Venice, south of Tampa Bay.

For the Hurricane Andrew simulations, we focus on point 8551, located near Biscayne Bay (Figure 3-14). Like the previous four simulations, the three cases begin with nearly identical surges while the hurricane is far from shore. The wave set-up and mass transport levels then drastically rise and reach maximum surges 60 percent higher than the wind-forcing only test. The three series then converge at the end of the simulation. At this particular location, the 


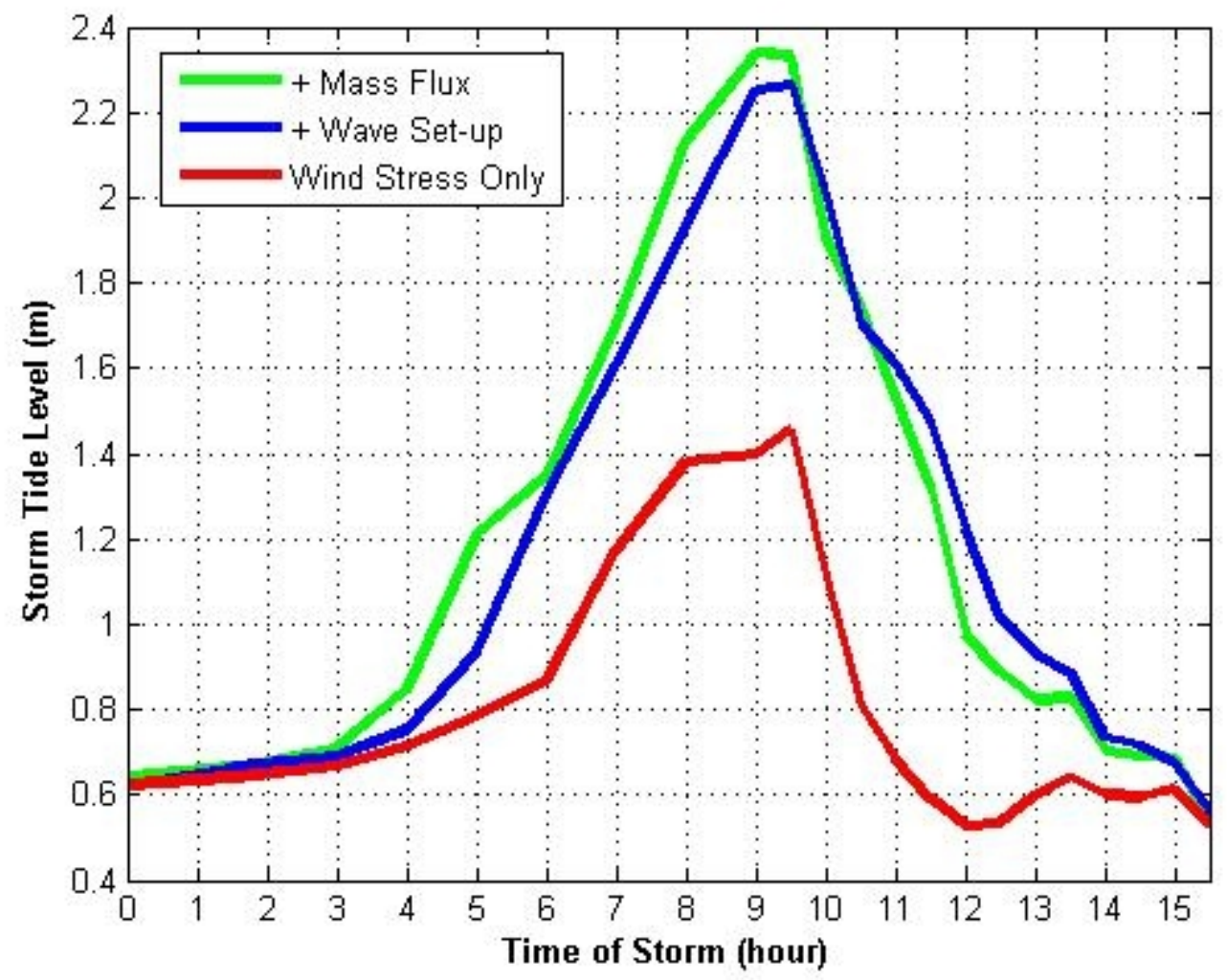

Figure 3-14: Surge levels at each time step at point 8551 in the HMIA basin for Hurricane Andrew simulations of each forcing option. This point is located near Biscayne Bay, south of Miami.

test with mass flux forcing does not deviate much from the wave and wind stress forcing results.

Like the tests on the Tampa Bay basin, wave effects neutralize wind-forced surge at certain positions. At point 11408, wave forcing tests yield surge levels smaller than wind-only forcing throughout the storm. In fact, the maximum levels deviate by nearly 80 percent $(0.4 \mathrm{~m}$ versus $0.05 \mathrm{~m})$. Clearly, localized effects can effect the impact of wave forcing as much or more than the basin's overall bathymetry.

\subsubsection{Overland Inundation}

The last method of temporal analysis is the comparison of the average overland surges and inundation extent for each of the forcing options. Figure 3-15A shows the hourly average 
surge levels and Figure 3-15B displays the number of inundated land points each hour for the Category 1 tests. For the first eight hours of the storm, all land points remain "dry," with no storm surge present. All three profiles then drastically increase, as surge from both wind and waves reaches the coast. At the $13^{\text {th }}$ hour, one hour after landfall, maximum average overland surge occurs, with highest levels from the mass flux case, then wave set-up case, and finally the wind-only case. However, the maximum number of inundated points is not reached until the $15^{\text {th }}$ hour, showing that maximum spatial coverage will not necessarily occur at either the times of landfall or of highest overland average surge.
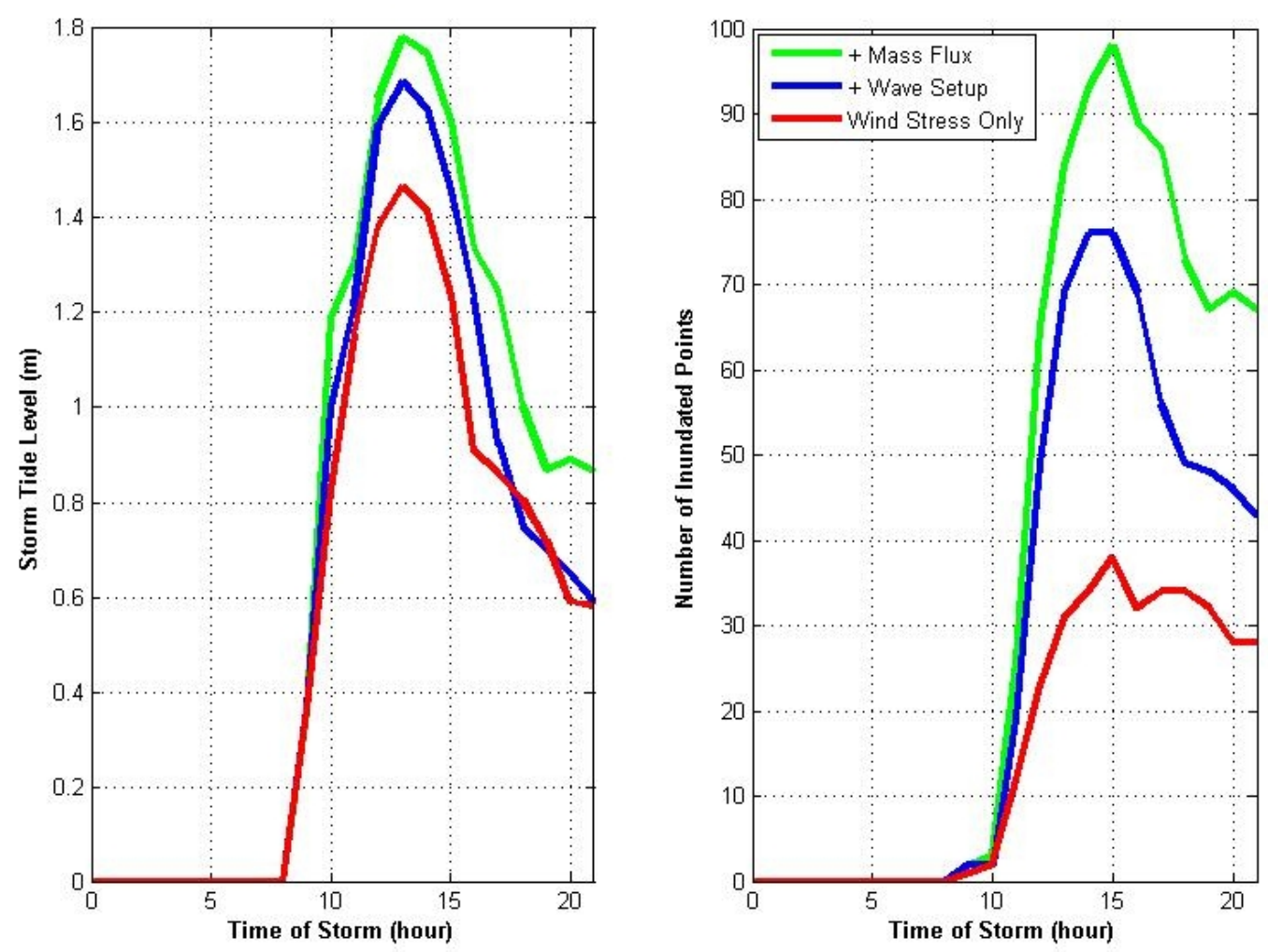

Figure 3-15: Time series hourly results for A) average overland storm tide levels and B) number of inundated overland points for the Category 1 tests on ETPA basin.

For the Category 4 testing, the time series graphs (Figure 3-16) reveal an analogous result to the Category 1 simulations. No overland inundation occurs until the seventh hour, at which 
time all three forcing averages dramatically increase. All cases do see a brief decrease during the ninth hour due to an approximate 25 percent weakening in the storm's maximum winds in the eigth hour. This same depreciation occurs in the Category 1 storm, but it is more pronounced in the Category 4 results because of the 1.75 scaling of the wind velocities. Like the Category 1 tests, overland averages reach maximum levels at the $13^{\text {th }}$ hour in each case. The number of inundated points follows a similar pattern as well, but the gap between the mass flux and windonly forcing tests is much less pronounced due to land topography.
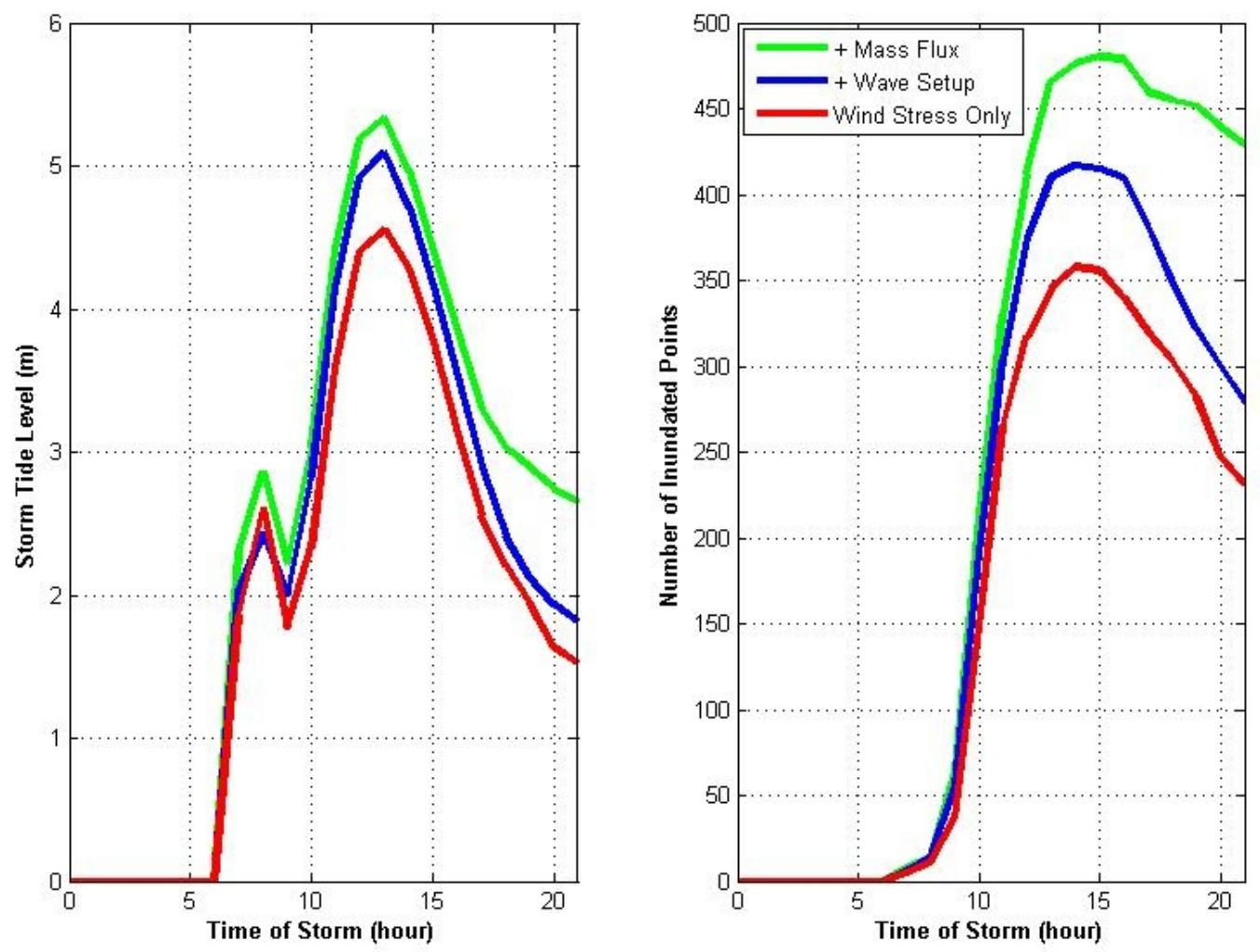

Figure 3-16: Time series hourly results for A) average overland storm tide levels and B) number of inundated overland points for the Category 4 tests on ETPA basin.

The overland surge results for Hurricane Andrew are shown in Figure 3-17. Unlike the Tampa Bay simulations, the overland surge begins above zero because of the sea level datum ( 2 feet) used by SLOSH. The overall pattern of coastal inundation does closely follow the previous 
testing, with a dramatic rise as the storm nears landfall followed by a gentle receding of flood waters. The mass-flux-included case does show a dramatic increase in number of inundated points, flooding greater than 60 percent more points than the unedited SLOSH test.
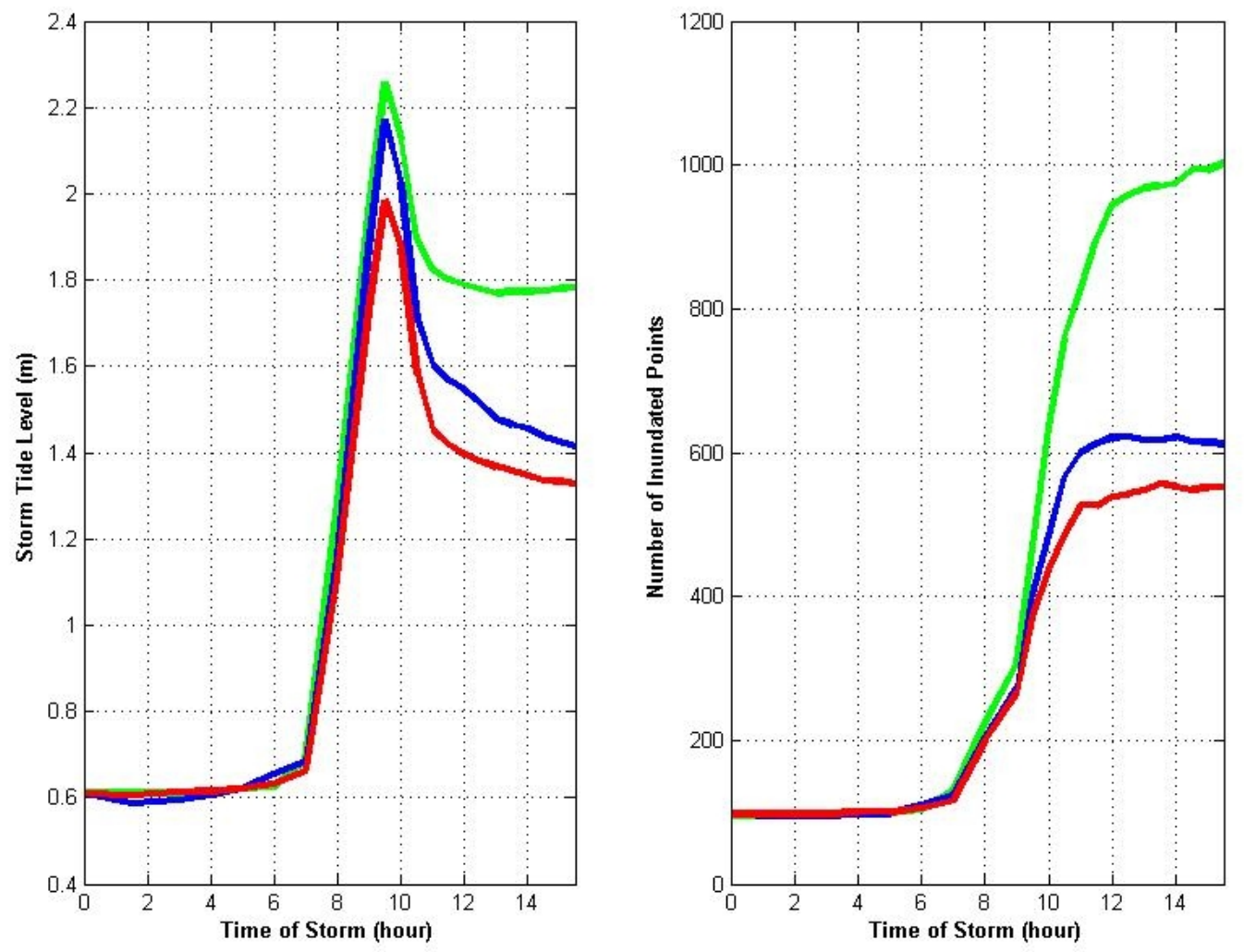

Figure 3-17: Time series hourly results for A) average overland storm tide levels and B) number of inundated overland points for Hurricane Andrew on HMIA basin.

\subsection{HURRICANE ANDREW HINDCAST}

As mentioned in Section 1.4, the hindcast tests of Hurricane Andrew could not be compared temporally to any real-time records since no NOAA buoys were active in the region at the time. Other than qualitative looks at the derived storm surge maps, the only meaningful quantitative comparison to be performed is of the storm surge levels recorded at Burger King Headquarters at SW $184^{\text {th }}$ St. in Miami, Florida. Andrew's maximum surge level of 16.9 feet 
$(5.15 \mathrm{~m})$ was recorded at this location. HMIA point 6042 was the closest grid position to this place. Figure 3-18 is a time series of the surges computed with each forcing option at this position. The maximum surge level for the wind-stress-only test is $4.00 \mathrm{~m}$, whereas the levels for the wave set-up and mass flux tests are $4.40 \mathrm{~m}$ and $4.53 \mathrm{~m}$, respectively. The inclusion of just wave set-up effects improved the prediction by 12 percent; inclusion both wave forcing components improved the prediction by another 3 percent.

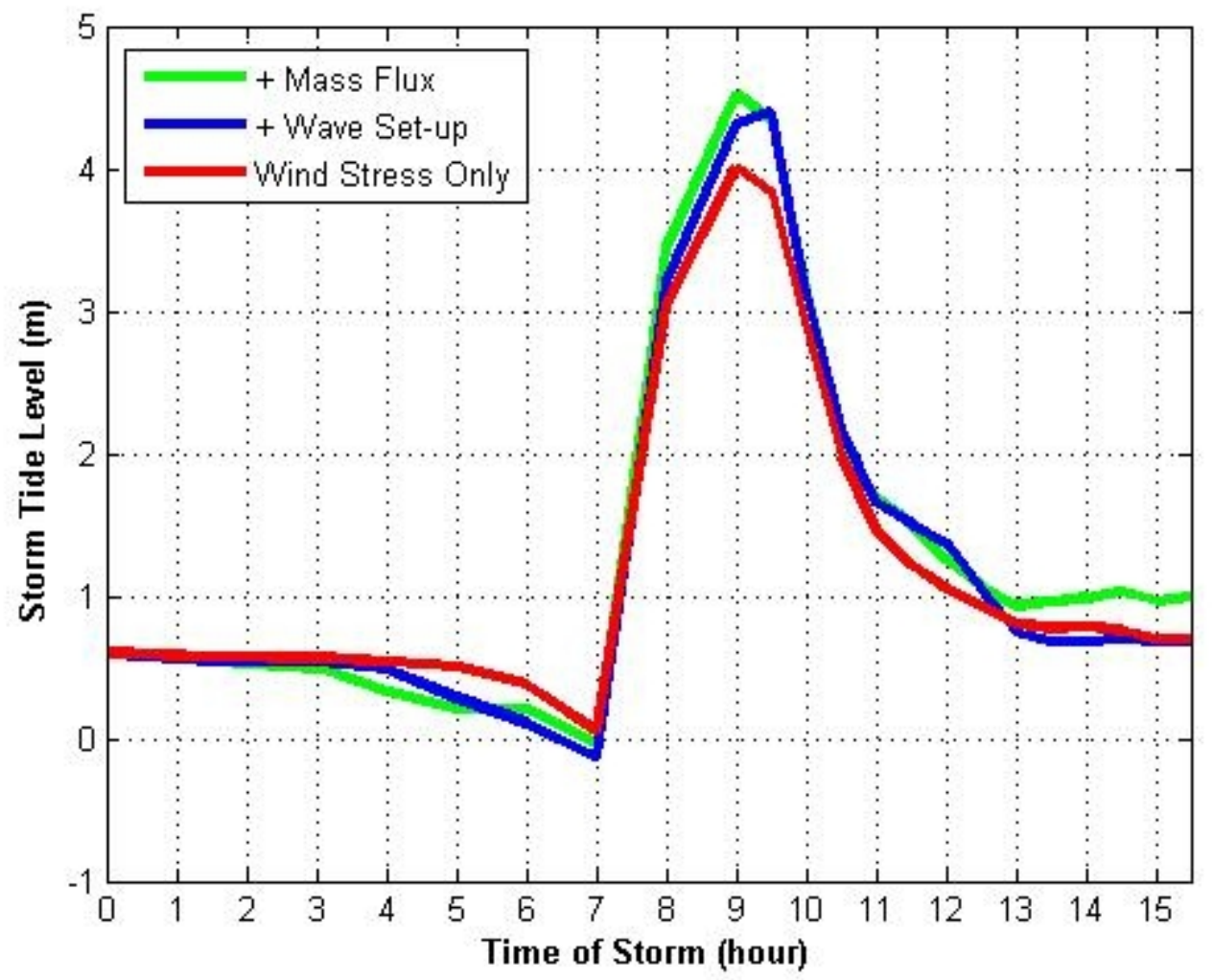

Figure 3-18: Surge levels at each time step at point 6042 in the HMIA basin for Hurricane Andrew simulations of each forcing option. This point is the closest grid location to the Burger King Headquarters on SW $184^{\text {th }}$ Street in Miami, where maximum surge levels of $5.15 \mathrm{~m}$ were recorded.

In summary, the results show that the effect of wave forcing in the storm surge model is highly location dependent. Waves can have large effects, such as at point 9569 in the Miami basin. At other positions, however, wave forces yield no significant change to wind-only forcing 
predictions. Still at other locations, wave interactions reduce the surge levels. On a domainwide level, however, the inclusion of waves does result in larger maximum levels and more inland inundation. Temporally, waves cause maximum levels to be reached slightly earlier, on the order of one hour, for the storms tested. Also, for coastal locations, we typically see higher surge levels after the storm has passed caused by greater overland inundation. 


\section{CHAPTER 4}

\section{CONCLUSIONS}

The two-way coupling of the SLOSH storm surge and the SWAN third-generation wave models demonstrated that the addition of wave forcing can produce surges that are 10 to 30 percent higher than observed in the absence of this coupling. Moreover, some coastal locations could expect a 50 to 100 percent increase in surge levels. Each wave component, wave set-up effects and mass flux transport, yielded similar increases. However, these results are highly dependent on coastal characteristics such as local bathymetry and geometry, as well as the influence of bays and barrier islands.

\subsection{BATHYMETRY}

Previous studies of wave effects on storm surge have found that waves influence surge levels more on steep shelves than mild, gentle slopes (WEAVER, 2004). The opposite trend was found in our study. By every measure, the wave forcing in similar strength hurricanes produced nearly identical or higher surges on the gentle slope of the Gulf. The wave stress outputs from SWAN had maximum values that are five times greater than those observed for Hurricane Andrew than the Category 4 storm at Tampa Bay on their respective SWAN Cartesian grids. This is reasonable because the wave breaking zone is more narrow on the steep shelf leading to a more intense localized zone. The differences between the two bay geometries, as well as the diameter and forward speed of the storm, can explain the differences in the overall response of the system. A balance between computational efficiency and adequate grid spacing is sufficiently achieved as long as the surge and wave grids are of comparable resolution so that no momentum transfer from the wave to the surge is lost due to aliasing of the signal in the 
interpolation process. Momentum is conserved on any size of control volumes, though second order effects can generally be captured better on higher resolution grids. As the SLOSH surge grids increase in resolution in the future, corresponding increases in the SWAN wave grids will also be necessary. The optimal grid calibration for accurate prediction differs based on individual basin and storm characteristics. Adequate resolution between the shoreline out to a distance where the largest generated waves from the strongest hurricane simulation break would be optimal for accurate inclusion of wave forces.

\subsection{STORM STRENGTH}

The wave forces caused a larger percent increase in surge levels for the weaker storm. Most of this difference occurs because of the relative importance of wind-stress in each case; over mild slopes, wind stress contributes much more to surge levels. For instance, a 75 percent growth of the maximum winds leads to a 250 percent increase in maximum surge levels. On the other hand, stronger hurricanes produced bigger waves that break farther from the coast. Thus, although the wave stress and mass flux transports are higher, they are imparted into the water column sooner and, thus, dissipated at a higher rate. Hence, one could expect an optimal condition of wave effects based on the storm strength over the same bathymetry. Wave effects will grow as a depression turns into a hurricane but ultimately decline as the hurricane becomes a behemoth storm.

\subsection{SIGNIFICANCE OF WAVE SET-UP AND MASS FLUX}

Wave set-up and mass flux are important contributers to the physics of storm surge modeling, although they are often neglected in favor of computational efficiency. Wave stresses 
caused an increase of 6 percent to the maximum surge levels; a combination of mass flux and wave stresses yielded a 17 percent gain. This result is very near to the extent of SLOSH's accepted error range. Individual storms and basins are likely to experience maximum level increments much higher than these averages.

We have shown that the impact of these forces can vary from location to location. Some locations will experience a significant rise in surge levels, others will remain relatively unchanged, while still other locations will see a decrease in storm surge. In the absence of coupling the SWAN and SLOSH models, it would be an impossible task to identify which of the above categories a specific location would be, a fact that testifies to the necessity of wave inclusion. A blanket coefficient or linear combination could closely predict maximum surges with wave forces, but neither option could adequately capture the complex interaction between each forcing component and the basin's and storm's characteristics.

Overland surge predictions are extremely valuable to evacuation planning, risk assessment, and construction design for coastal infrastructure. In our tests, wave forcing raised the average inundation levels between 10 and 35 percent. As many as twice as many grid points became flooded when wave forcing was considered. For the Tampa Bay simulation, this change was equivalent to approximately 90 square miles of additional inundation around the Bay. Additionally, this extra inundation would cause a larger area to remain inundated longer as the surge recedes, an important result for emergency relief plans.

\subsection{HISTORICAL COMPARISON}

Real-time records of sea level elevations from buoy data were not available for the hindcast of Hurricane Andrew. However, we could compare the results from the three forcing cases at the maximum surge location. Here, inclusion of mass flux and wave set-up effects 
improved the prediction by 15 percent. A further improvement would be seen with more refined grids in the storm surge model.

\subsection{FUTURE STUDY}

In addition to improving SLOSH's nearshore grid resolution, we plan to focus on other basins and test storms to arrive at a better comprehension of the complex relationships between wind and wave forcing. Additional testing and improvement of the bottom slip and drag coefficients are needed to better represent the physics of storm surge. We also plan to install a nested grid system in SWAN. A coarse resolution grid (at least 4 kilometer grid spacing) would cover the entire SLOSH grid, and a fine resolution grid (2 kilometer spacing) would be fitted nearshore to capture the momentum transfer from breaking waves. Such a system would improve computational efficiency while preserving the general physics of hurricane-generated waves. 


\section{APPENDIX A}

The following files are the TRK files used during our simulations. The first file is the one used for the Tampa Bay storms. The same TRK file (etpa_SLOSHtrk998) was used for the Category 1 and 4 scenarios, only the maximum winds were scaled by a factor of 1.75 for the stronger hurricane. The second TRK file represents a hindcast of Hurricane Andrew. The columns for each file correspond to the following variables: track point, latitude, longitude, wind speed (mph), storm direction and speed (knots), pressure change (from ambient) (mb), radius of maximum winds (statute miles), actual STM points (MCINERNEY, 2006).

SLOSH Track ID: etpa_SLOSHtrk998

Derived from HRD Simulated Track etpa_storm0004388 (36 pts)

$\begin{array}{llllllll}\text { NAP---- } & 125.9500 & 84.350 & 13.00 & 25.42 & 31.11 & 20.24 & 1-- \text { NAP } \\ 2 & 26.1200 & 84.260 & 12.67 & 29.26 & 31.37 & 20.40 & 2 \\ 326.2800 & 84.160 & 16.99 & 35.59 & 30.62 & 20.43 & 3 \\ 426.4800 & 84.000 & 16.98 & 35.55 & 29.87 & 20.49 & 4 \\ 526.6800 & 83.840 & 17.54 & 34.19 & 29.12 & 20.54 & 5 \\ 626.8900 & 83.680 & 16.96 & 35.45 & 28.37 & 20.59 & 6 \\ 727.0900 & 83.520 & 16.95 & 35.40 & 27.62 & 20.64 & 7 \\ 827.2900 & 83.360 & 17.51 & 34.04 & 26.87 & 20.69 & 8 \\ 927.5000 & 83.200 & 12.14 & 37.20 & 26.83 & 20.85 & 9 \\ 1027.6400 & 83.080 & 13.06 & 37.47 & 26.79 & 20.97 & 10 \\ 1127.7900 & 82.950 & 12.69 & 35.24 & 26.76 & 21.10 & 11 \\ 12 & 27.9400 & 82.830 & 12.68 & 35.20 & 26.76 & 21.22 & 12 \\ 1328.0900 & 82.710 & 12.68 & 35.17 & 26.35 & 21.28 & 13 \\ 1428.2400 & 82.590 & 12.67 & 35.13 & 25.96 & 21.34 & 14 \\ 1528.3900 & 82.470 & 11.95 & 41.29 & 25.56 & 21.41 & 15 \\ 1628.5200 & 82.340 & 12.36 & 43.37 & 25.18 & 21.45 & 16 \\ 1728.6500 & 82.200 & 12.35 & 43.33 & 24.80 & 21.50 & 17 \\ 1828.7800 & 82.060 & 11.93 & 41.18 & 24.42 & 21.54 & 18\end{array}$




\begin{tabular}{|c|c|c|c|c|c|c|}
\hline$)$ & & & & & & \\
\hline 400 & 700 & 15 & 39.02 & 23.69 & 2164 & \\
\hline 0 & 60 & 80 & 49.27 & .33 & 9 & \\
\hline 0 & 50 & 8 & .23 & 98 & & \\
\hline & 260 & 32 & 47.35 & 22.63 & & \\
\hline & 060 & 16.31 & 50.51 & 22.94 & & \\
\hline & & .50 & 26 & 23.24 & & \\
\hline & $\varepsilon$ & 15.82 & 05 & 23.55 & & \\
\hline & 8 & 13.11 & 4 & 23.52 & & \\
\hline & 8 & 9 & 69 & 23.49 & & \\
\hline & 80 & 13.09 & 46.67 & 23.46 & & \\
\hline & 79. & 3.07 & 2 & 23.43 & & \\
\hline ) & 79.7 & 13.07 & 0 & 23.40 & & \\
\hline ) & 79.6 & 13.05 & 5 & 23.37 & & \\
\hline 0 & 79.460 & 15.02 & 7 & 23.13 & & \\
\hline 0 & 79.220 & 1 & 73.69 & 22.88 & 3 & \\
\hline 0 & 78.980 & 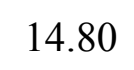 & 8 & 22.64 & & \\
\hline 0 & 78.7 & 0.0 & & 22.40 & & \\
\hline 0 & 78.740 & 0.00 & 0.00 & 2.40 & & \\
\hline & 78 & 0.0 & & 2.40 & & \\
\hline & 78 & & & 0 & & \\
\hline & 78 & 0. & 0.0 & .40 & & \\
\hline & 7 & & & 0 & & 9 \\
\hline 0 & 78.740 & 0.00 & 0.00 & 22.40 & & \\
\hline 0 & 78.740 & 0.00 & مـ & 22.40 & 23.35 & 21 \\
\hline 43 & 78.740 & 0.00 & مـ & 22.40 & 23.35 & \\
\hline 1531.0400 & 78.740 & 0.00 & 0.00 & 22.40 & 23.35 & 23 \\
\hline 100 & 78.740 & c & 0.0 & 22.40 & 25.53 & \\
\hline 00 & 78. & 0.00 & .00 & 22.40 & 23.35 & 25 \\
\hline .0400 & 78.7 & 0.00 & 0.00 & 22.40 & 5 & \\
\hline & & & & .40 & & \\
\hline 40 & 18.14 & U & .00 & 22.40 & 23.35 & \\
\hline
\end{tabular}




\begin{tabular}{|c|c|c|c|c|c|c|}
\hline 0 & 78.740 & 0.00 & 0.00 & 2.40 & 5 & \\
\hline ) & 78.7 & 00 & .00 & 2.40 & 5 & \\
\hline & 78.740 & & 00 & 0 & & \\
\hline & 78.740 & & & 0 & & \\
\hline & 78.740 & & 0 & & & \\
\hline & 78.740 & & & & & \\
\hline & 78.740 & & & & & \\
\hline ) & 78.740 & 0 & .00 & & & \\
\hline ) & 78.7 & 0 & .00 & 0 & & \\
\hline 0 & 740 & 0 & Oم & 0 & & \\
\hline 0 & 740 & 0 & .00 & 0 & & \\
\hline 0 & 740 & 0 & .00 & 0 & & \\
\hline & 7 & 0 & .00 & 2.40 & & \\
\hline & 7 & 0.00 & 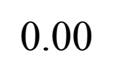 & 0 & & \\
\hline & 78.740 & 0.00 & 0.00 & 22.40 & & \\
\hline & 0 & 0.00 & .00 & 22.40 & & \\
\hline & 40 & 0.00 & .00 & .40 & & \\
\hline & 40 & 0.00 & .00 & 22.40 & & \\
\hline & 7 & 000 & .00 & 22.40 & & \\
\hline & 7 & 00 & .00 & 22.40 & & \\
\hline 0 & 78.7 & 0.00 & .00 & 22.40 & 35 & \\
\hline 0 & 78.7 & 0.00 & 0.00 & 22.40 & 35 & \\
\hline 400 & 78.740 & 0.00 & 0.00 & 22.40 & 35 & \\
\hline 431.0400 & 78.740 & 0.00 & 0.00 & 22.40 & 5 & \\
\hline 7531.0400 & 78.740 & 0.00 & 0.00 & 22.40 & 5 & \\
\hline 400 & 78.740 & 0.00 & 0.00 & 22.40 & 5 & \\
\hline 400 & 78.740 & 0.00 & 0.00 & 22.40 & 2 & \\
\hline 1.0400 & 78.740 & 0.00 & 0.00 & 22. & & \\
\hline 7931.0400 & 78.740 & 0.00 & 0.00 & 22.40 & 5 & \\
\hline .0400 & 78.740 & 0.00 & 0.00 & 22.40 & 35 & \\
\hline 813 & 78.740 & 0.00 & 0.00 & 22.40 & 23.35 & \\
\hline 8231.0400 & 78.740 & 0.00 & .00 & 2.40 & 35 & \\
\hline
\end{tabular}




$\begin{array}{rlllllll}8331.0400 & 78.740 & 0.00 & 0.00 & 22.40 & 23.35 & 61 \\ 8431.0400 & 78.740 & 0.00 & 0.00 & 22.40 & 23.35 & 62 \\ 8531.0400 & 78.740 & 0.00 & 0.00 & 22.40 & 23.35 & 63 \\ 8631.0400 & 78.740 & 0.00 & 0.00 & 22.40 & 23.35 & 64 \\ 8731.0400 & 78.740 & 0.00 & 0.00 & 22.40 & 23.35 & 65 \\ 8831.0400 & 78.740 & 0.00 & 0.00 & 22.40 & 23.35 & 66 \\ 8931.0400 & 78.740 & 0.00 & 0.00 & 22.40 & 23.35 & 67 \\ 9031.0400 & 78.740 & 0.00 & 0.00 & 22.40 & 23.35 & 68 \\ 9131.0400 & 78.740 & 0.00 & 0.00 & 22.40 & 23.35 & 69 \\ 9231.0400 & 78.740 & 0.00 & 0.00 & 22.40 & 23.35 & 70 \\ 9331.0400 & 78.740 & 0.00 & 0.00 & 22.40 & 23.35 & 71 \\ 9431.0400 & 78.740 & 0.00 & 0.00 & 22.40 & 23.35 & 72 \\ 9531.0400 & 78.740 & 0.00 & 0.00 & 22.40 & 23.35 & 1 \\ 9631.0400 & 78.740 & 0.00 & 0.00 & 22.40 & 23.35 & 2 \\ 9731.0400 & 78.740 & 0.00 & 0.00 & 22.40 & 23.35 & 3 \\ 9831.0400 & 78.740 & 0.00 & 0.00 & 22.40 & 23.35 & 4 \\ 9931.0400 & 78.740 & 0.00 & 0.00 & 22.40 & 23.35 & 5 \\ 10031.0400 & 78.740 & 0.00 & 0.00 & 22.40 & 23.35 & 6 \\ 1231 & \text { IBGNT ITEND JHR } & & & \end{array}$

HR1200 20 SEP 2333 NEAREST APPROACH, OR LANDFALL, TIME $0.0 \quad 0.0 \quad$ SEA AND LAKE DATUM

HURRICANE "ANDREW": BRJ "BEST TRACK \#4" $\quad$ DATUMS = 2.0 FT.

DELTA-P = 87MB:(1013-926 MB); RMW=09. ST MI.; WEST 18 MPH.

$\begin{array}{llllllll}125.3914 & 62.252 & 15.59 & 270.05 & 71.00 & 9.00 & 1 \\ 225.3918 & 62.502 & 15.59 & 270.05 & 71.00 & 9.00 & 2 \\ 325.3922 & 62.752 & 15.59 & 270.05 & 71.00 & 9.00 & 3 \\ 425.3927 & 63.002 & 15.59 & 270.05 & 71.00 & 9.00 & 4 \\ 525.3931 & 63.252 & 15.59 & 270.05 & 71.00 & 9.00 & 5 \\ 625.3935 & 63.502 & 15.59 & 270.05 & 71.00 & 9.00 & 6 \\ 725.3939 & 63.752 & 15.59 & 270.05 & 71.00 & 9.00 & 7 \\ 825.3943 & 64.001 & 15.59 & 270.05 & 71.00 & 9.00 & 8\end{array}$




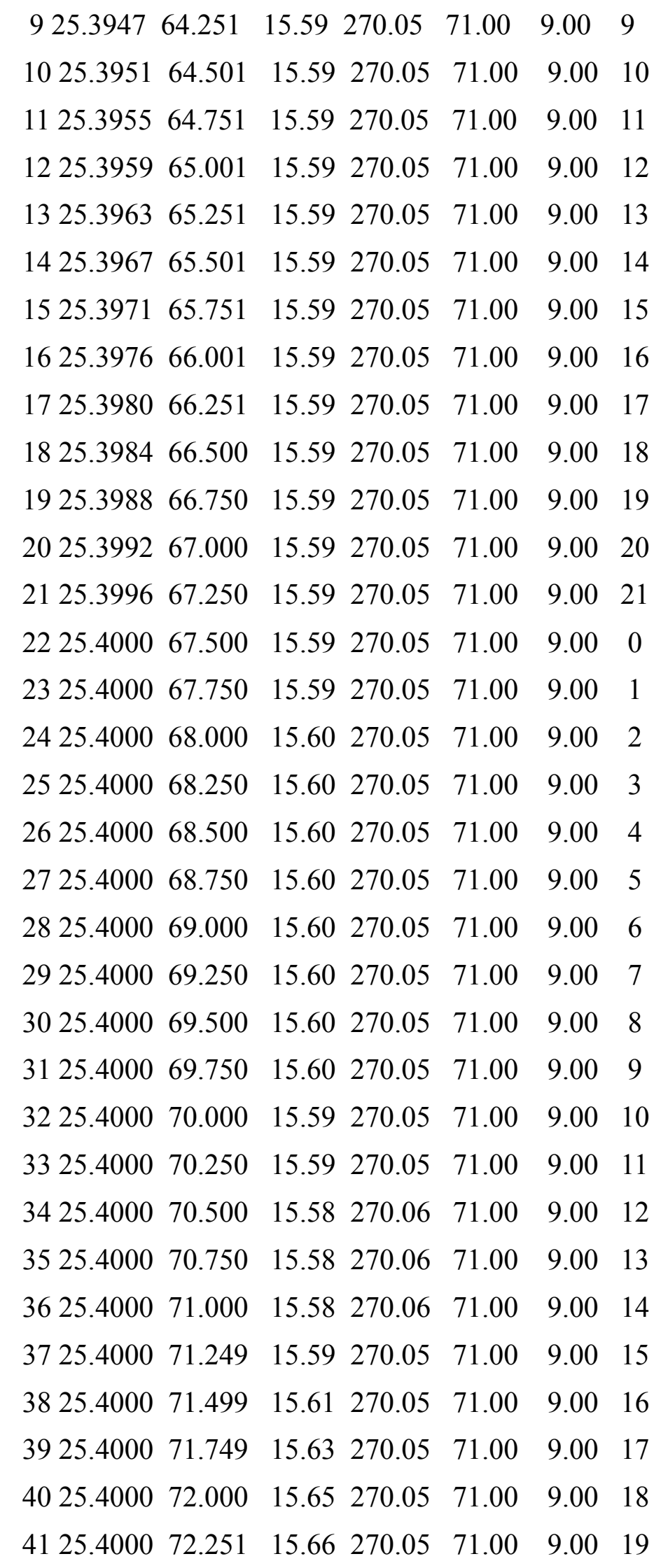




\begin{tabular}{|c|c|c|c|c|c|c|c|}
\hline & 4225.3999 & 72.502 & 15.64 & 270.05 & 71.00 & 9.00 & 20 \\
\hline & 4325.3999 & 72.753 & 15.61 & 270.05 & 71.00 & 9.00 & 21 \\
\hline & 4425.3999 & 73.003 & 15.55 & 270.06 & 71.00 & 9.00 & 22 \\
\hline & 4525.3999 & 73.252 & 15.47 & 270.07 & 71.00 & 9.00 & 23 \\
\hline & 4625.4000 & 73.500 & 15.39 & 270.08 & 71.00 & 9.00 & 24 \\
\hline & 4725.4001 & 73.747 & 15.37 & 270.08 & 71.00 & 9.00 & 25 \\
\hline & 4825.4002 & 73.993 & 15.43 & 270.08 & 71.00 & 9.00 & 26 \\
\hline & 4925.4003 & 74.241 & 15.56 & 270.06 & 71.00 & 9.00 & 27 \\
\hline & 5025.4003 & 74.490 & 15.77 & 270.03 & 71.00 & 9.00 & 28 \\
\hline & 5125.4002 & 74.743 & 16.05 & 270.00 & 71.00 & 9.00 & 29 \\
\hline & 5225.4000 & 75.000 & 16.40 & 269.96 & 71.00 & 9.00 & 30 \\
\hline & 5325.3996 & 75.263 & 16.77 & 269.96 & 71.00 & 9.00 & 31 \\
\hline & 5425.3992 & 75.532 & 17.15 & 269.98 & 71.00 & 9.00 & 32 \\
\hline & 5525.3988 & 75.807 & 17.55 & 270.04 & 71.00 & 9.00 & 33 \\
\hline & 5625.3988 & 76.088 & 17.95 & 270.14 & 71.00 & 9.00 & 34 \\
\hline & 5725.3991 & 76.376 & 18.36 & 270.25 & 71.00 & 9.00 & 35 \\
\hline & 5825.4000 & 76.670 & 18.77 & 270.39 & 71.00 & 9.00 & 36 \\
\hline & 5925.4016 & 76.971 & 19.09 & 270.54 & 71.00 & 9.00 & 37 \\
\hline & 6025.4038 & 77.277 & 19.31 & 270.68 & 71.00 & 9.00 & 38 \\
\hline & 6125.4068 & 77.586 & 19.43 & 270.82 & 71.00 & 9.00 & 39 \\
\hline & 6225.4105 & 77.898 & 19.45 & 270.96 & 71.00 & 9.00 & 40 \\
\hline & 6325.4149 & 78.210 & 19.36 & 271.11 & 71.00 & 9.00 & 41 \\
\hline & 6425.4200 & 78.520 & 19.18 & 271.27 & 71.00 & 9.00 & 42 \\
\hline & 6525.4258 & 78.827 & 18.96 & 271.46 & 73.67 & 9.00 & 43 \\
\hline & 6625.4325 & 79.131 & 18.70 & 271.68 & 76.33 & 9.00 & 44 \\
\hline & 6725.4402 & 79.431 & 18.41 & 271.94 & 79.00 & 9.00 & 45 \\
\hline & 6825.4489 & 79.726 & 18.08 & 272.23 & 81.67 & 9.00 & 46 \\
\hline & 6925.4588 & 80.016 & 17.73 & 272.56 & 84.33 & 9.00 & 47 \\
\hline NAP----- & 7025.4700 & 80.300 & 17.38 & 272.97 & 87.00 & 9.00 & 48 ---NAP \\
\hline & 7125.4828 & 80.578 & 17.21 & 273.53 & 82.83 & 9.50 & 49 \\
\hline & 7225.4979 & 80.854 & 17.27 & 274.27 & 78.67 & 10.00 & 50 \\
\hline & 7325.5162 & 81.130 & 17.57 & 275.14 & 74.50 & 10.50 & 51 \\
\hline & 7425.5388 & 81.411 & 18.09 & 276.12 & 70.33 & 11.00 & 52 \\
\hline
\end{tabular}




$\begin{array}{llllllll}75 & 25.5664 & 81.700 & 18.84 & 277.14 & 66.17 & 11.50 & 53 \\ 7625.6000 & 82.000 & 19.76 & 278.11 & 62.00 & 12.00 & 54 \\ 7725.6400 & 82.314 & 20.53 & 278.75 & 61.67 & 12.00 & 55 \\ 7825.6849 & 82.640 & 21.09 & 279.03 & 61.33 & 12.00 & 56 \\ 79 & 25.7324 & 82.975 & 21.43 & 278.99 & 61.00 & 12.00 & 57 \\ 80 & 25.7805 & 83.315 & 21.55 & 278.66 & 60.67 & 12.00 & 58 \\ 81 & 25.8271 & 83.658 & 21.46 & 278.01 & 60.33 & 12.00 & 59 \\ 82 & 25.8700 & 84.000 & 21.20 & 277.13 & 60.00 & 12.00 & 60 \\ 8325.9077 & 84.339 & 20.96 & 276.33 & 60.00 & 12.00 & 61 \\ 84 & 25.9408 & 84.674 & 20.78 & 275.72 & 60.00 & 12.00 & 62 \\ 85 & 25.9704 & 85.007 & 20.66 & 275.31 & 60.00 & 12.00 & 63 \\ 86 & 25.9977 & 85.339 & 20.60 & 275.10 & 60.00 & 12.00 & 64 \\ 8726.0238 & 85.669 & 20.60 & 275.10 & 60.00 & 12.00 & 65 \\ 88 & 26.0500 & 86.000 & 20.64 & 275.28 & 60.00 & 12.00 & 66 \\ 8926.0771 & 86.331 & 20.69 & 275.49 & 60.00 & 12.00 & 67 \\ 9026.1054 & 86.663 & 20.74 & 275.69 & 60.00 & 12.00 & 68 \\ 9126.1348 & 86.996 & 20.80 & 275.90 & 60.00 & 12.00 & 69 \\ 9226.1654 & 87.330 & 20.85 & 276.11 & 60.00 & 12.00 & 70 \\ 9326.1971 & 87.665 & 20.90 & 276.31 & 60.00 & 12.00 & 71 \\ 9426.2300 & 88.000 & 20.90 & 276.31 & 60.00 & 12.00 & 72 \\ 95 & 26.2629 & 88.335 & 20.90 & 276.31 & 60.00 & 12.00 & 1 \\ 9626.2957 & 88.671 & 20.90 & 276.31 & 60.00 & 12.00 & 2 \\ 9726.3286 & 89.007 & 20.90 & 276.31 & 60.00 & 12.00 & 3 \\ 9826.3615 & 89.342 & 20.90 & 276.31 & 60.00 & 12.00 & 4 \\ 10026.4272 & 90.014 & 20.90 & 276.31 & 60.00 & 12.00 & 6\end{array}$

617770

IBGNT ITEND JHR

HR0500 24 AUG 1992 NEAREST APPROACH, OR LANDFALL, TIME

$\begin{array}{lll}2.0 & 2.0 \quad \text { SEA AND LAKE DATUM }\end{array}$ 


\section{APPENDIX B}

The following is an example of the input file used to implement SWAN for the Tampa Bay tests. From this input file, SWAN reads the appropriate water level, wind, and bathymetric data and then calculates the wave fields at the prescribed time intervals.

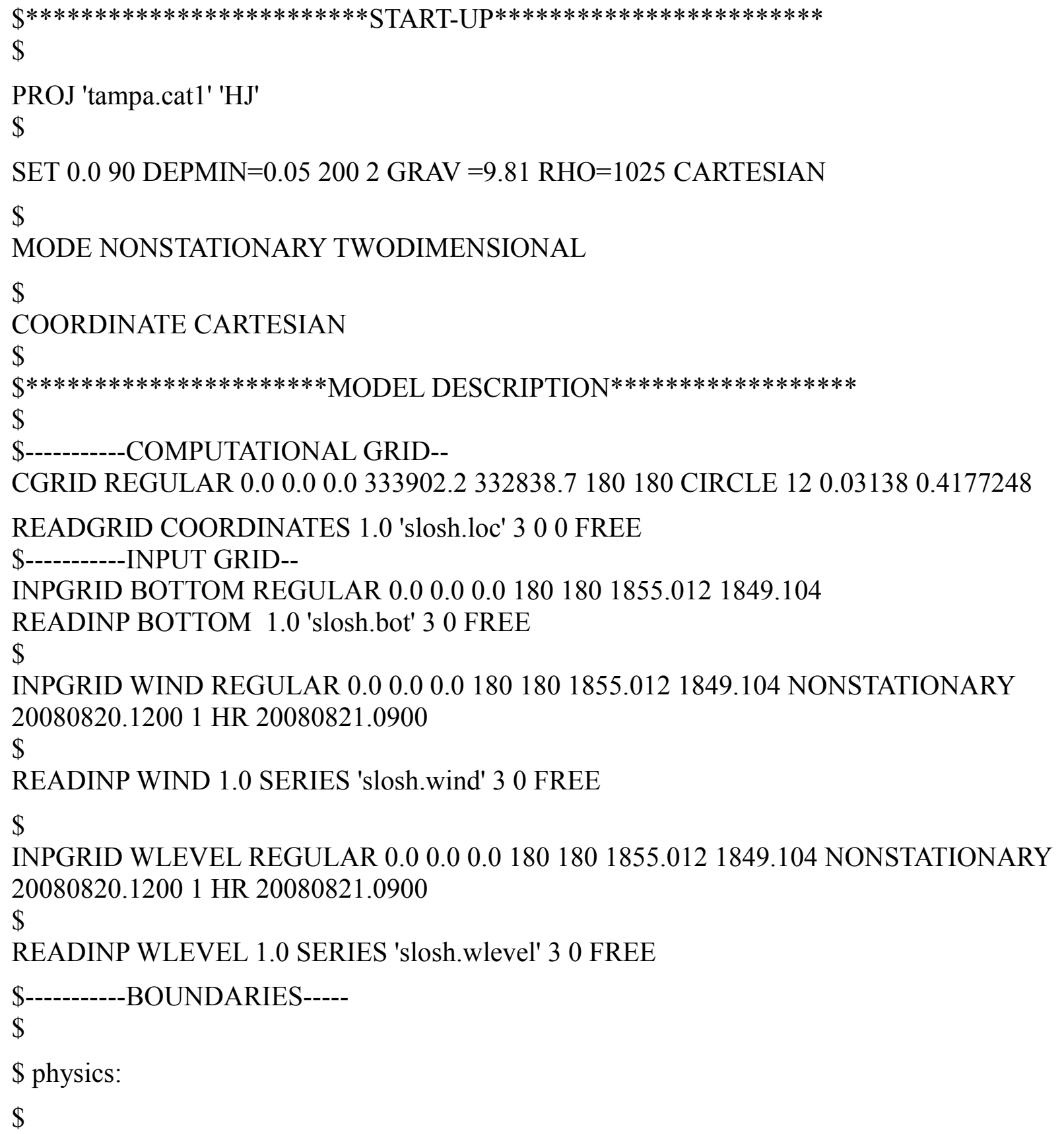


SETUP

GEN3

FRICTION

TRIAD 0.12 .00 .20 .01

QUAD

PROP

BSBT

$\$$

NUMERIC ACCUR DREL $=0.02$ DHOVAL $=0.02$ DTOVAL $=0.02$ NPNTS $=90.0$ NONSTAT 1000.1

$\$$

$\$$

$\$ * * * * * * * * * * * * * * * * * * * * * * * * * * * * \mathrm{OUTPUT} * * * * * * * * * * * * * * * * * * * * * * * *$

$\$$

OUTPUT OPTIONS ' ' TABLE 16 BLOCK 6121

FRAME 'OUT' 0.00 .00 .0333893 .3332838 .7180180

TABLE 'OUT' NOHEAD 'out' XP YP WIND FORCE DEPTH HSIGN DIR PER RTP OUTPUT 20080820.1200 1 HR

$\$$

COMPUTE STAT 20080820.1200

COMPUTE NONSTAT 20080820.1200 1 HR 20080821.0900

$\$$

STOP 


\section{REFERENCES}

Anthes, R.A., 1982. Tropical Cyclones, Their Evolution Structure and Effects. Boston, Massachusetts: American Meteorological Society, 208p. 1.1

Booij, N.; Haagsma I.J.G.; Holthuijsen, L.H.; Kieftenburg, A.T.M.M.; Ris, R.C.; van der Westhuysen, A.J., and Zijlema, M., 2004. SWAN Cycle III version 40.45 User Manual. Delft, The Netherlands: Delft University of Technology, 115p. 1.3, 2.2

Dean, R.G. and Dalrymple, R.A, 1991. Water Wave Mechanics for Engineers and Scientists. River Edge, New Jersey: World Scientific Press, 353p. 1.1 .3

Dean, R.G. and Dalrymple, R.A. 2002. Coastal Processes with Engineering Applications. Cambridge, United Kingdom: Cambridge University Press, 488p. 1.1.2

Donelan, M.A., 1998. Air-water exchange processes. Coastal and Estuarine Studies, 54, 19-36. 1.1 .1

Donelan, M.A.; Dobson, F.W.; Smith, S.D., and Anderson, R.J., 1993. On the dependence of sea surface roughness on wave development. Journal of Physical Oceanography, 23, 2143-2149. 1.1.1

Geernaert, G.L., 1990. Bulk Parameterizations for the Wind Stress and Heat Fluxes. In: Geernaert, G.L. and Plant, W.J. (ed.), Surface Waves and Fluxes I. Dordrecht, The Netherlands: Kluwar Academic Publishers, pp. 91-172. 1.1.1

Grachev, A.A.; Fairall, C.W.; Hare, J.E.; Edson, J.B., and Miller, S.D., 2003. Wind stress vector over ocean waves. Journal of Physical Oceanography, 33, 2408-2429. 1.1.1

Herbert, P.J., Jarrell, J.D and Mayfield, M., 1992. The deadliest, costliest, and most intense hurricane of this century (and other frequently requested facts). Washington, DC: National Oceanic Atmospheric Administration Technical Memorandum NHC 31, 31 p. 1.4

Holland, G.J., 1993. Ready Reckoner. In: Holland, G.J. (ed.), Global Guide to Tropical Cyclone Forecasting. Geneva, Switzerland: World Meteorological Organization. (http://www.bom.gov.au/bmrc/pubs/tcguide/globa_guide_intro.htm) 1.1

Jelesnianski, C.P., 1967. Numerical Computations of Storm Surges with Bottom Stress. Monthly Weather Review, 95, 740-756. 2.1

Jelesnianski, CP. and TAYlor, A.D., 1973. A preliminary view of storm surges before and after storm modifications. Washington, D.C: National Oceanic Atmospheric Administration Technical Memorandum ERL WMPO-3, 33p. 2.1.2

Jelesnianski, C.P., 1992. SLOSH: Sea, Lake, and Overland Surges from Hurricanes. Silver 
Spring, Maryland: National Oceanic Atmospheric Administration Technical Report NWS 48, 71p. 1.2, 2.1, 2.1.1, 3.2.1

Kantha, L.H. and Clayson, C.A., 2000. Numerical Models of Oceans and Oceanic Processes. New York: Academic Press, 940p. 1.1

KnabB, R.D., Rhome, J.R., and Brown D.P., 2006. Tropical Cyclone Report, Hurricane Katrina 23 - 30 August 2005. Miami, Florida: National Oceanic Atmospheric Administration, National Hurricane Center, 43p. 1.1

Landsea, C.W.; Franklin, J.L.; McAide, C.J.; Beven II, J.L.; Gross, J.M.; Jarvinen, B.R.; Pasch, R.J.; Rappaport, E.N.; Dunion, J.P., and Dodge, P.P., 2004. A Reanalysis of Hurricane Andrew's Intensity. Bulletin of the American Meteorological Society, 85(11), 1699-1712. 1.4

Longuett-Higgins, M.S. and Stewart, R.W., 1964. Radiation stresses in water waves; a physical discussion with applications. Deep-Sea Research, 11, 529-562. 1.1.2

Myers, V.A. and Malkin, W. 1961. Some properties of hurricane wind fields as deduced from trajectories. National Oceanic Atmospheric Administration, National Hurricane Research Project Report 49, 43p. 2.1.2

Pasch, R.J.; Blake E.S.; Cobb III, H.D., and Roberts D.P., 2006. Tropical Cyclone Report, Hurricane Wilma 15 - 25 October 2005. Miami, Florida: National Oceanic and Atmospheric Administration, National Hurricane Center, 27p. 1.1

PINET, P.R., 1998. Invitation to Oceanography. Boston, Massachusetts: Jones and Bartlett Publishers, 576p. 1.1

Phan, L.T.; Simiu, E.; McInerney, M.A.; Taylor, A.A.; Glahn, B.; Powell, M.D., 2007. Methodology for development of design criteria for joint hurricane wind speed and storm surge events: proof of concept. National Institute of Standards and Technology, NIST Technical Note 1482, 45p.

Platzman, G.W. 1963. The dynamic prediction of wind tides on Lake Erie. Meteorological Monographs, 4(26), 44p. 2.1

McInerney, M.A., 2006. SLOSH Sea, Lake, and Overland Surges from Hurricanes User \& Technical Software Documentation. Silver Spring, Maryland: National Oceanic and Atmospheric Administration, National Weather Service, 171p. 2.1.3, Appendix A

Rappaport, E.N., 1993. Preliminary Report, Hurricane Andrew, 16 - 28 August 1992. Miami, Florida: National Oceanic Atmospheric Administration, National Hurricane Center. (http://www.nhc.noaa.gov/1992andrew.html) 1.4

Sмiтн, J.A., 2006. Wave-Current Interactions in Finite Depth. Journal of Physical Oceanography, 36, 1403-1419. 1.1.2, 2.3 
STARR, V.P., 1947. A momentum integral for surface waves in deep water. Journal of Marine Research, 6(2), 126-135. 1.1.2

WeAver, R.J., 2004. Effect of Wave Forces on Storm Surge. Gainesville, Florida: University of Florida, Master's thesis, 76 p. 1.1.1, 3.3.2, 4.1

WhitakeR, R.E.; ReID, R.O., and VASTANo, A.C., 1975. An analysis of drag coefficient at hurricane windspeeds from a numerical simulation of dynamical water level changes in Lake Okeechobee, Florida. U.S. Army Corps of Engineers Technical Report 56, 108p. 2.1 